\title{
Long-Term Temporal Imprecision of Information Coding in the Anterior Cingulate Cortex of Mice with Peripheral Inflammation or Nerve Injury
}

\author{
Xiang-Yao Li, ${ }^{1,2}$ Ning Wang, ${ }^{3}$ Yong-Jie Wang, ${ }^{1}$ Zhen-Xing Zuo, ${ }^{1}$ Kohei Koga, ${ }^{2}$ Fei Luo, ${ }^{3}$ and Min Zhuo ${ }^{1,2}$ \\ ${ }^{1}$ Center for Neuron and Disease, Frontier Institute of Science and Technology, Xi'an Jiaotong University, Xi'an, Shaanxi 710054, China, ${ }^{2}$ Department of \\ Physiology, Faculty of Medicine, University of Toronto, The Center for the study of Pain, Toronto, Ontario M5S 1A8, Canada, and 3Key Laboratory of \\ Mental Health, Institute of Psychology, Chinese Academy of Sciences, Beijing 100101, China
}

\begin{abstract}
Temporal properties of spike firing in the central nervous system (CNS) are critical for neuronal coding and the precision of information storage. Chronic pain has been reported to affect cognitive and emotional functions, in addition to trigger long-term plasticity in sensory synapses and behavioral sensitization. Less is known about the possible changes in temporal precision of cortical neurons in chronic pain conditions. In the present study, we investigated the temporal precision of action potential firing in the anterior cingulate cortex (ACC) by using both in vivo and in vitro electrophysiological approaches. We found that peripheral inflammation caused by complete Freund's adjuvant (CFA) increased the standard deviation (SD) of spikes latency (also called jitter) of $\sim 51 \%$ of recorded neurons in the ACC of adult rats in vivo. Similar increases in jitter were found in ACC neurons using in vitro brain slices from adult mice with peripheral inflammation or nerve injury. Bath application of glutamate receptor antagonists $\mathrm{CNQX}$ and AP5 abolished the enhancement of jitter induced by CFA injection or nerve injury, suggesting that the increased jitter depends on the glutamatergic synaptic transmission. Activation of adenylyl cyclases (ACs) by bath application of forskolin increased jitter, whereas genetic deletion of $\mathrm{AC} 1$ abolished the change of jitter caused by CFA inflammation. Our study provides strong evidence for long-term changes of temporal precision of information coding in cortical neurons after peripheral injuries and explains neuronal mechanism for chronic pain caused cognitive and emotional impairment.
\end{abstract}

Key words: chronic pain; cingulate cortex; cortex; mice; synaptic transmission; temporal precision

\section{Introduction}

The temporal property of spike firing is tightly connected to the cognitive function of brain (Fetz, 1997; Rutishauser et al., 2010; Szatmáry and Izhikevich, 2010). In the CNS, the sequence of the action potentials (APs) firing of presynaptic and postsynaptic neurons will determine the synaptic strength. Moreover, the temporal precision of the spikes firing within population neurons affects the generation and traveling of oscillation which has been linked to the strength of long-term memory (Harris et al., 2003; Ermentrout et al., 2008; Colgin et al., 2009; Rutishauser et al., 2010). A recent study showed that temporal precision of information coding was dynamically changed by experience or neuronal properties, for example, removal of whiskers enhanced the reliability

Received Dec. 10, 2013; revised June 13, 2014; accepted June 30, 2014.

Author contributions: M.Z. designed research;X.-Y.L., N.W.,Y.-J.W.,Z.-X.Z., and K.K. performed research;X.-Y.L.,

Y.-J.W., K.K., and F.L. analyzed data; X.-Y.L., K.K., and M.Z. wrote the paper.

This work is supported by grants from Canada Research Chair, CIHR operating Grant 258523, NSEC Discovery Grant RGPIN402555, and The Azrieli Foundation and Brain Canada (M. Z.). X.-Y.L. was supported by 973 program for young scientists (No. 2014CB548200). K.K. was supported by a postdoctoral fellowship from FragileX Research Foundation of Canada.

The authors declare no competing financial interests.

This article is freely available online through the J Neurosci Author Open Choice option.

Correspondence should be addressed to Dr Min Zhuo, Department of Physiology, University of Toronto, Faculty of

Medicine, Medical Science Building, Room 3342, 1 King's College Circle, Toronto, ON M5S 1A8, Canada. E-mail: min.zhuo@utoronto.ca.

DOI:10.1523/JNEUROSCI.5166-13.2014

Copyright $\odot 2014$ the authors $\quad 0270-6474 / 14 / 3410675-13 \$ 15.00 / 0$ and precision of spike firing on neurons in superficial layer of barrel cortex (Benedetti et al., 2009). In the hippocampus, the temporal lobe epilepsy decreased the temporal precision of excitatory postsynaptic potentials (EPSPs)-spike coupling in dentate granule cells which may be dependent on the interplay between aberrant kainate receptor-mediated EPSP and persistent sodium current $\left(\mathrm{I}_{\mathrm{NaP}}\right.$; EpsZtein et al., 2010). Therefore, the temporal precision of spikes firing is involved in the regulation of cognition by different mechanisms.

Chronic pain is known to interfere with higher brain functions, such as cognition, decision making, and emotion. Using an animal model of chronic inflammation, we reported that trace fear memory was impaired after peripheral inflammation (Zhao et al., 2006). Similarly, it has been reported that both inflammatory pain and neuropathic pain impaired the food-reinforced spatial working memory and context fear memory (Mutso et al., 2012) due to the reduced hippocampus-prefrontal connectivity (Cardoso-Cruz et al., 2013a,b). Long-term potentiation of synaptic transmission has been reported in several major cortical areas that are critical for pain and pain-related responses, such as the ACC medial prefrontal cortex (mPFC), and insular cortex (Zhao et al., 2006; Xu et al., 2008; Li et al., 2010; for review, see Zhuo, 2008, 2013). However, less is known whether the temporal precision of information coding in cortical regions may be impaired after peripheral injuries.

In the present study, we used both in vivo and in vitro electrophysiological approaches to investigate whether the temporal 
precision of information coding of the ACC neurons is affected after peripheral inflammation or nerve injury. We also examined the contribution of potentiated synaptic responses to possible alternation of the firing latency and temporal precision of spike firing in brain slice preparation. Our study provides strong evidence that temporal precision of information processing in the ACC neurons are reduced after peripheral injury, and such changes in neuronal properties may explain why certain types of cognitive and emotional functions are impaired in patients suffering chronic pain.

\section{Materials and Methods}

Animals. Adult (8-12 weeks of age) C57BL/6 mice were housed individually and maintained on a $12 \mathrm{~h}$ light/dark cycle. Fifteen Sprague-Dawley male rats (3 months) weighting 250-300 g were used for in vivo electrophysiological recording. Food and water were provided ad libitum. To induce inflammatory pain, $10 \mu \mathrm{l}$ of 50\% Complete Freund' Adjunt (CFA, Sigma-Aldrich) was injected subcutaneously into the plantar surface of left hindpaw of mice, and $100 \mu \mathrm{l}$ of the same concentration of CFA was injected for rats. The animal care and use committee of University of Toronto and Xi'an Jiaotong University approved all animals' protocols.

Animal surgery. Following anesthesia with sodium pentobarbital (50 $\mathrm{mg} / \mathrm{kg}$, i.p.), rats were transferred to a Kopf stereotaxic apparatus. Supplementary doses (1/3 of the original) of ketamine were given when necessary. Four small craniotomies in one side of the brain were made for microelectrode array implantation. According to the atlas of Paxinos and Waston (1998), stereotaxic coordinates were as follows: (1) for the medial-dorsal thalamus (MD), $2.3 \mathrm{~mm}$ posterior to bregma, $0.8 \mathrm{~mm}$ lateral to midline (L), and $5.5 \mathrm{~mm}$ ventral to the skull surface $(\mathrm{V}),(2)$ for the ACC, 3.2 A, 0.8 L, and 2.8 V. Arrays of eight stainless steel Tefloninsulated microwires (50 $\mu \mathrm{m}$ diameter, Biographics) were slowly lowered into the target areas. The microelectrode arrays were secured onto the cranium with stainless steel skull screws and dental cement. Animals were administered penicillin (16,000 U, i.m.) before surgery to prevent infection. Rats were allowed 1 week to recover from the surgical procedure.

In vivo electrophysiological data acquisition. Neuronal activities were detected by the microwires and passed from the headset assemblies to a preamplifier via a light-weight cable. Single-unit activities and behavioral data were recorded using a 128-channel data acquisition system (Cerebus, Blackrock Microsystems). The sampled signals were analog filtered by the amplifier at cutoff frequencies of $0.3 \mathrm{~Hz}$ and $7.5 \mathrm{kHz}$. The signals from each microelectrode were amplified and bandpass filtered $(250 \mathrm{~Hz}$ to $5 \mathrm{kHz}$ ). Neural signals were digitized with 16 -bit resolution at $30 \mathrm{kHz}$ using Cerebus Neural signal processor and sorted using spike-sorting programs. The time stamps of the spike activities were saved into a data base file for off-line analysis. Spiking activity was extracted from the digitized recordings, and individual units were isolated offline using Plexon Offline Sorter. A single unit was defined by homogenous waveforms quantified by sets of waveform parameters clustered in a multidimensional parameter space. The stability of single unit was based on criteria including the separation of waveform clusters on principle component axes and homogeneity of waveforms (Zhang et al., 2011; Steenland et al., 2012).

In vivo electrical stimulation protocol. During the recording session, rats were awake and moving freely. Electrical stimuli were generated by a stimulator Master-8 and DC powered isolator ISO Flex (AMPI), applied through the electrode in MD. The parameters were as follows: intensity $0.1 \mathrm{~mA}$, pulse width $200 \mu$ s, frequency $10 \mathrm{~Hz}$ with 5 pulses per train, interspike interval $20 \mathrm{~s}$ and 50 trains per session.

Neuropathic pain mouse model. A model of neuropathic pain was induced as previously described (Vadakkan et al., 2005). Briefly, mice were anesthetized by intraperitoneal injection of a mixture saline of ketamine $(0.16 \mathrm{mg} / \mathrm{kg}$; Bimeda-MTC) and xylazine $(0.01 \mathrm{mg} / \mathrm{kg}$; Bayer $)$. The common peroneal nerve $(\mathrm{CPN})$ was visible between anterior and posterior groups of muscles running almost transversely. The left $\mathrm{CPN}$ was ligated with chromic gut suture 5-0 (Ethicon) slowly until contraction of the dorsiflexors of the foot was visible as twitching of the digits. The skin was sutured using 5-0 silk suture and cleaned with povione iodine. Sham surgery was conducted in the same manner but the nerve was not ligated. All animals were kept in a $37^{\circ} \mathrm{C}$ warming chamber connected to a pump (Gaymar T/Pump) for at least $1 \mathrm{~h}$ postsurgery. The mice were used for behavioral test on postsurgical days 3-14.

Slice preparation. Mice were anesthetized with halothane. The brain was then quickly removed and submerged in cold, oxygenated artificial CSF (ACSF) containing the following (mM): $124 \mathrm{NaCl}, 2.5 \mathrm{KCl}, 0.5$ $\mathrm{CaCl}_{2}, 2 \mathrm{MgSO}_{4} 25 \mathrm{NaHCO}_{3}, 1 \mathrm{NaH}_{2} \mathrm{PO}_{4}$, and 10 glucose. Coronal slices (300 $\mu \mathrm{m}$ thick) containing the ACC were prepared using standard methods (Wu et al., 2005; Zhao et al., 2006). Slices were cut with a vibratome section system (VT 1000), and transferred to submerged recovery chamber with oxygenated $\left(95 \% \mathrm{O}_{2}\right.$ and $\left.5 \% \mathrm{CO}_{2}\right)$ ACSF containing the following (in mM): $124 \mathrm{NaCl}, 2.5 \mathrm{KCl}, 2 \mathrm{CaCl}_{2}, 1 \mathrm{MgSO}_{4} 25 \mathrm{NaHCO}_{3}, 1$ $\mathrm{NaH}_{2} \mathrm{PO}_{4}$, and 10 glucose at room temperature for at least $1 \mathrm{~h}$.

Whole-cell patch-clamp recording. Experiments were performed in a recording chamber on the stage of a BX61W1 microscope equipped with infrared differential interference contrast optics for visualization. The recording pipettes $(2-3 \mathrm{M} \Omega$ ) were filled with a solution containing the following (in mM): $120 \mathrm{~K}$-gluconate, $5 \mathrm{NaCl}, 1 \mathrm{MgCl}_{2}, 0.2 \mathrm{EGTA}, 10$ HEPES, $2 \mathrm{Mg}$-ATP, $0.1 \mathrm{Na}_{3}$-GTP, 10 phosphocreatine disodium (adjusted to $\mathrm{pH} 7.2$ with $\mathrm{KOH}$ ). Whole-cell recording were performed at room temperature $\left(24 \pm 1^{\circ} \mathrm{C}\right)$ using a patch-clamp amplifier (multiclamp 700B, Molecular Devices). Data were filtered at $2 \mathrm{kHz}$ and digitized at $20 \mathrm{kHz}$ using the digidata $1322 \mathrm{~A}$.

Compound EPSCs. The simulated EPSCs (sEPSCs) were synthesized following a $\beta$ function (Rodriguez-Molina et al., 2007): $I(t)=\lambda[\exp (-t)$ $\tau$ decay $)-\exp (-t / \tau$ rise $)]$. Where $\lambda$ is the amplitude of sEPSCs, $t$ is time, and rise and $\tau$ decay are the rise and decay time constant, respectively (Rodriguez-Molina et al., 2007). During the experiments, the gain of sEPSCs was changed, and the amplitude of sEPSCs was adjusted to just induce the AP firing.

Histology. Animals were deeply anesthetized with pentobarbital sodium $(60 \mathrm{mg} / \mathrm{kg}$ body weight, i.p.) and were perfused intracardially with $200 \mathrm{ml}$ of sterile saline, followed by $400 \mathrm{ml}$ of fixative containing $4 \%$ paraformaldehyde in $0.1 \mathrm{~m}$ phosphate buffer (PB; $\mathrm{pH} 7.4)$. The brain was removed and postfixed in the same fixative for $16 \mathrm{~h}$, and then cryoprotected in $0.1 \mathrm{M} \mathrm{PB}$ containing $20 \%$ sucrose until the tissue sank to the bottom of the container. The brains were sunk in $30 \%$ sucrose and were stored at $4^{\circ} \mathrm{C}$ until sectioning. Frozen serial coronal sections $(30 \mu \mathrm{m}$ thick) were cut with a cryostat and mounted on gelatin-coated glass slides. The slides were stained with hematoxylin and eosin for verification of electrodes placement in the ACC and the MD.

Data analysis. Off-line analysis was performed using Clampfit 9. Sigmaplot 11.0 was used to plot and fit the data. Statistical comparisons were made using the $t$ test, one-way or two-way ANOVA (Student-Newmann-Keuls test was used for post hoc comparison), One-way or twoway repeated-measures ANOVA (Holm-Sidak method was used for multiple comparison). All data were presented as the mean \pm SEM. In all cases, $p<0.05$ is considered statistically significant.

\section{Results}

\section{In vivo electrophysiological recording of adult rat \\ ACC neurons}

To characterize the responses of cingulate neurons to peripheral noxious stimuli, we first performed multiple extracellular units recordings on cingulate neurons from freely moving rats at $8 \mathrm{~d}$ after the implantation of recording electrodes (Fig. 1Aa). Twenty-six cingulate neurons from three rats were recorded and the locations of electrode tips are shown in Figure $1 \mathrm{Ab}$. Among them, 10 cingulate neurons $(38.5 \%, 10 / 26)$ were excited by applying noxious heat to the hindpaw (Fig. $1 B$ ). The averaged firing rate was increased by noxious heat. Eight neurons showed decreased firing rate when peripheral noxious heat was applied (Fig. $1 C$ ), whereas the rest eight neurons did not show any change of firing rate (Fig. 1D). Thus, cingulate neurons can be grouped into three different types according to their responses to peripheral noxious heat: excited (Fig. 1C; 38.5\%, 10/26), inhibited (Fig. 1D; 
A

a

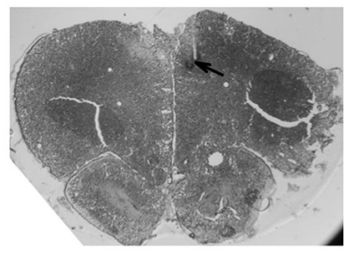

C

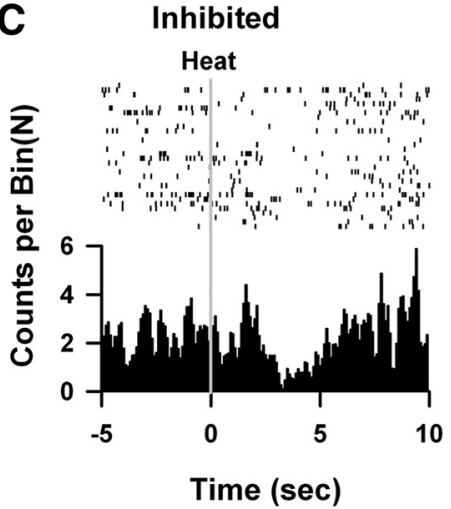

b
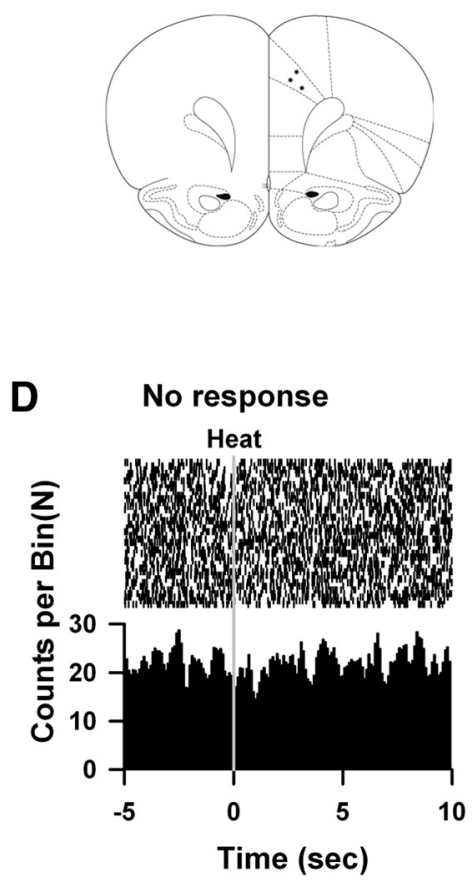

B

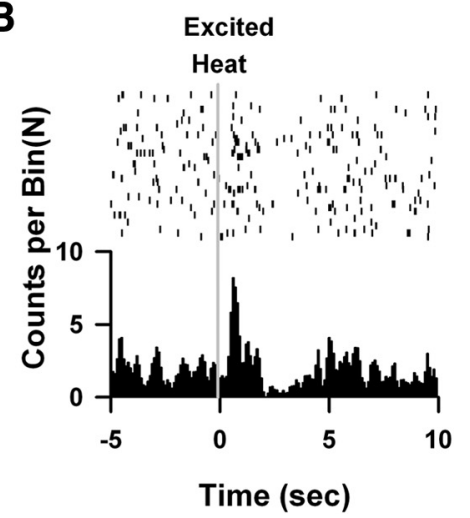

$\mathbf{E}$

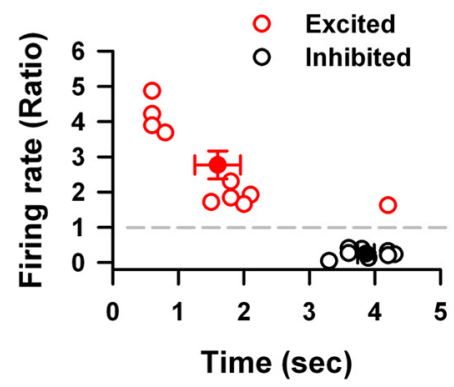

Figure 1. The heating noxious response of the ACC neurons in vivo. Aa, The hematoxylin-eosin staining of the ACC. Arrows indicated the recording sites $\boldsymbol{A b}$, The schematic diagram showed the distributions of recording sites in the $A C C . B$, Example shows one excited response neuron under heating stimulation. Firing frequency was significantly increased within two seconds after heating stimulation. Each vertical indicates one spike. $\boldsymbol{C}$, One example of the inhibited neurons that showed inhibiting effects on the spikes firing under heating stimulation. $\boldsymbol{D}$, Example shows one cingulate neuron which did not response to heating nociceptive stimulations, upper raster plot showed the relative firing time of spikes, dashed line indicating start of heating stimulations. The lower part showed the histogram of spikes in the upper part. $\boldsymbol{E}$, The changed ratio and peak latency of excited neurons (filled circle) and inhibited neurons (open circle), each gray circle indicates one neuron, and black circles presented the summarized data.

$30.8 \%, 8 / 26$ ), and no response (Fig. $1 B ; 30.8 \%, 8 / 26$ ). For excited neurons, the firing frequency of spikes increased to $2.77 \pm 0.40$ times of baseline at $1.60 \pm 0.35 \mathrm{~s}$ after the application of noxious heat (Fig. $1 E$ ). For inhibited neurons, the frequency of spikes was decreased to $0.25 \pm 0.04$ times of baseline at a longer latency (3.86 $\pm 0.13 \mathrm{~s})$.

To determine whether the temporal characteristics of information coding within the thalamic-cingulate circuit was changed by peripheral inflammation, we recorded the responses of cingulate neurons to electrical stimulation in the MD (Figure $2 A, B$ ). The perievents histogram was generated, and the relative latency of spike to the onset of stimuli was calculated. The temporal characteristics of response were presented by the averaged latency, the jitter of latency (the SD of latency, higher value indicates less temporal precision; Tiesinga et al., 2008) and coefficient variance (CV; variance divided by mean) of latency. We found almost all cingulate neurons responded to electrical stimulation applied in the thalamus. Figure $2 B$ shows one typical example of neuronal responses to electrical stimulations in the $\mathrm{MD}, \sim 86.7 \%$ of spikes occurred between 10 and $25 \mathrm{~ms}$ after the onset of electrical stimulations. The averaged spike latency of example neuron is $16.4 \mathrm{~ms}$, the jitter and CV of the latency is $2.7 \mathrm{~ms}$ and 0.093 , respectively. A total 47 recorded neurons were analyzed, the averaged latency of spikes firing under MD stimulation is $17.31 \pm$ $0.57 \mathrm{~ms}$ (Fig. $2 C$ ), the SD of the latency was $2.93 \pm 0.25 \mathrm{~ms}$ (Fig. $2 D$ ), and the CV of latency of the evoked spikes under MD stimulation was $0.17 \pm 0.01$ (Fig. $2 E$ ).
Peripheral inflammation decreased the temporal precision of spikes firing of neurons in the rat ACC

To investigate whether the temporal precision of information coding were affect by peripheral inflammation, we recorded the cingulate neuronal activities 1 or $3 \mathrm{~d}$ after saline or CFA injection. The injection of CFA significantly decreased the hindpaw withdrawal thresholds of rats tested 1 or $3 \mathrm{~d}$ after the injection, whereas the saline has no significant effect (saline: before, $10.58 \pm 0.90 \mathrm{~g}$, saline-1D, $10.56 \pm 0.69 \mathrm{~g}$, saline-3D, $10.26 \pm 1.01 \mathrm{~g}, n=6$ rats; CFA, before: $11.02 \pm 0.42 \mathrm{~g}$, CFA-1D, $4.34 \pm 0.38 \mathrm{~g}, \mathrm{CFA}-3 \mathrm{D}, 5.28 \pm 0.34 \mathrm{~g}, n=$ 7 rats, two-way repeated-measures ANOVA; $F_{(1,38)}=27.18, p<$ $0.01)$. The same thalamic stimuli were applied before or after CFA injection. The waveforms of spikes before and after injection were compared with confirm the same units were recorded (Fig. 3A). Thirty-seven neurons from CFA and 24 neurons from salineinjected mice were identified. Saline did not change the mean latency of the spikes (before: $15.97 \pm 1.14 \mathrm{~ms}$, saline-1D: $16.46 \pm 1.14 \mathrm{~ms}$, saline-3D: $16.29 \pm 1.10 \mathrm{~ms}$, one-way repeated-measures ANOVA; $F_{(2,71)}=2.62, p>0.05, n=24$ neurons), whereas CFA injection significantly decreased the mean latency (before CFA: $16.93 \pm 0.63 \mathrm{~ms}$, CFA1D: $16.41 \pm 0.61 \mathrm{~ms}$, CFA-3D: $16.31 \pm 0.48 \mathrm{~ms}$, one-way repeatedmeasures ANOVA; $F_{(2,110)}=4.45, p<0.05, n=37$ neurons).

The latency was then normalized by the averaged value before injection and data are presented in Figure $3 B$. The $\mathrm{CV}$ of the latency was significantly increased by CFA injection (one-way repeated-measures ANOVA, $F_{(2,110)}=5.07, p<0.05$; Fig. $3 C$ ) but not the saline group (one-way repeated-measures ANOVA; 
A

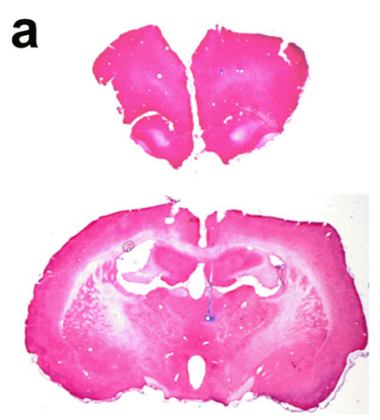

C

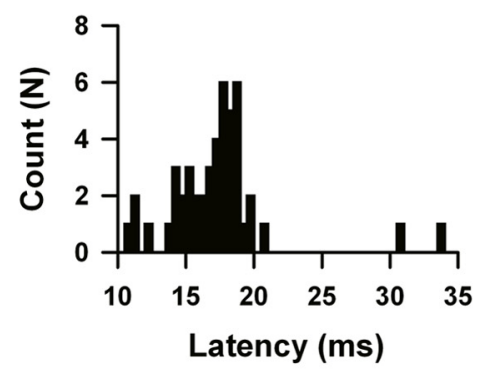

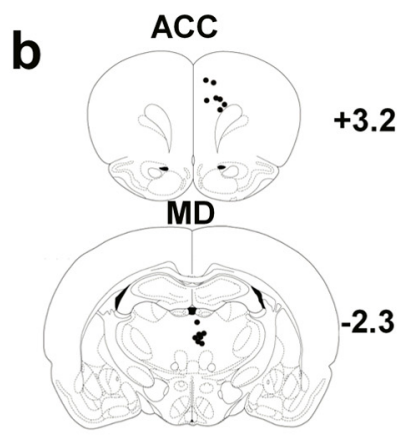

D

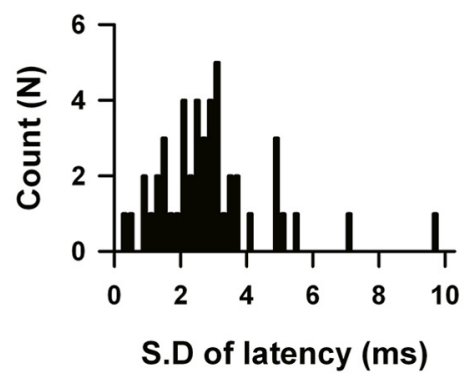

B

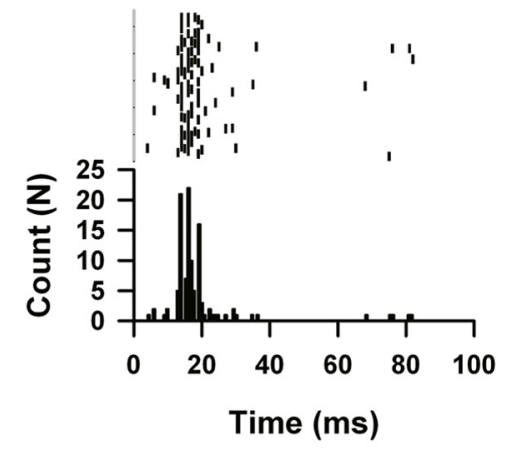

E

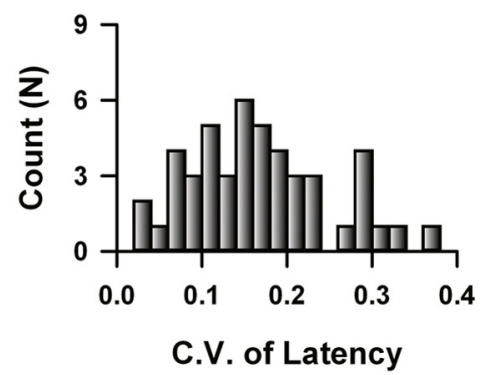

Figure 2. The spikes firing within thalamic-cingulate pathway of rats. Aa, The hematoxylin-eosin staining of the ACC (top) and medial-dorsal nucleus thalamus (bottom), receptively. Arrows indicated the recording sites (top) and stimulation sites (bottom). $\boldsymbol{A} \boldsymbol{b}$, The schematic diagram showed the distributions of recording sites in the $A C C$ and stimulation sites in thalamus. $\boldsymbol{B}$, The top raster plot showed the firing of the spikes recorded in the ACC in response to electrical stimulations in MD thalamus. The start of electrical stimulations was treated as time 0 , each vertical bar indicated one AP. The bottom shows the histogram of the relative firing time of the spikes firing in the upper part. C, Data show the frequency distribution of the firing latency of evoked responses under thalamic stimulations. D, Data show the frequency distribution of the jitter of latency of evoked responses under thalamic stimulations. $\boldsymbol{E}$, Data show the frequency distribution of the $C V$ of latency of cingulate response under thalamic stimulations.

$\left.F_{(2,71)}=1.28, p>0.05\right)$ tested at both time points. Among the recorded neurons, $\sim 51 \%$ of neurons (19/37) showed increased jitter at 1 and $3 \mathrm{~d}$ after CFA injection (Fig. $3 D, E$ ). Furthermore, the firing latency was decreased to $0.96 \pm 0.03$ and $0.96 \pm 0.02$ times of before injection by CFA, but not the saline group (Fig. $3 F$ ). These data suggest that CFA injection increased jitter and decreased firing latency on half of the recorded neurons for long time. For the other ACC neurons, mixed changes were found. Approximately 24\% (9/37) showed consistently decreased jitter (before: $3.79 \pm 0.85 \mathrm{~ms}$, CFA-1D: $3.07 \pm 0.75 \mathrm{~ms}$, CFA-3D: $3.08 \pm 0.66 \mathrm{~ms}, n=9$; Fig. $3 G, H)$, and no changed firing latency in CFA group (Fig. 3I). For the CFA group, 19\% (7/37) showed increased jitter at $1 \mathrm{~d}$, but came back to normal level $3 \mathrm{~d}$ after CFA injection (Fig. $3 J, K$ ), and no difference was detected on the firing latency (Fig. $3 L$ ), $\sim 6 \%$ (2/37) showed reverse change. For the saline group, three neurons showed increased jitter at $1 \mathrm{~d}$ but were normal 3 d later, three neurons showed reverse change. These results indicate that half of the cingulate neurons showed long-term temporal imprecision of thalamic-cingulate information coding after CFA injection.

\section{The temporal precision of action potentials recorded on the neurons of ACC in vitro}

In vitro preparations have been used to investigate the temporal precision of AP firing (Mainen and Sejnowski, 1995). We performed whole-cell patch-clamp recording on the neurons in layers II-III of the ACC. Figure $4 A$ shows one example of in vitro recording on neuron from saline-injected mice, steady-state currents which elicited five APs were injected into the recorded neu- rons, the firing of APs were aligned at the onset of currents stimulation, and the SD (also called jitter) of firing time of APs was calculated. As shown in Figure $4 A, B$, the jitter of the first APs was smaller than the fifth AP, the slope of jitter versus averaged AP firing time was calculated to indicate the jitter change (Fig. $4 B)$. To investigate the effects of current intensities on the temporal precision of AP firing, currents with different intensities (lower: 3; medium: 5; high: 8 or 9 APs) were injected. As shown in Figure $3 C$, the jitter of the first AP under lower stimulation intensity was significantly higher than others, and the currents intensities negatively correlated with slope of jitter $(r=0.54, p<$ $0.05, n=6$; Fig. 4C). Therefore, to avoid the effects of stimulation intensity on the jitter evaluation, in the following experiments, the intensities of test currents for the jitter calculation were set to which just induced five APs.

Different types of neurons have been reported in the prefrontal cortex of mice (Cao et al., 2009; Li et al., 2012). As shown in Figure $4 D$, three types of pyramidal neurons were recorded in layer II-III of the ACC based on the AP firing pattern. Briefly, the intermediate (IM) and regular spiking (RS) neurons were distinguished by the generation of afterdepolarization following the first APs (Fig. 4Da,Db), the intrinsic bursting (IB) neurons can generate burst following the first action potential (Fig. 4Dc). The jitter were calculated and no difference were detected on neither the jitter of APs (two-way ANOVA; $F_{(2,144)}=0.70, p>0.05$; Fig. $4 E$ ) nor the slope of jitter change among types (one-way ANOVA; $F_{(2,28)}=0.92, p>0.05$; Fig. $\left.4 F\right)$. Therefore, the temporal precision of the APs firing among different types of pyramidal neurons in the ACC was similar. 
A

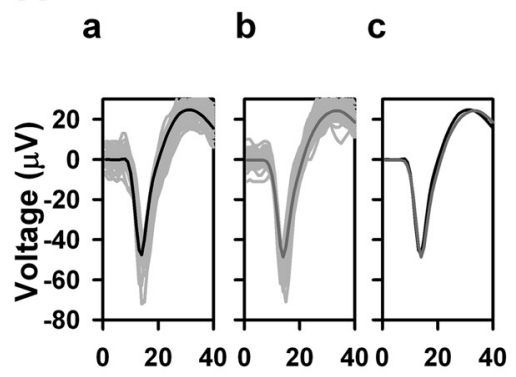

D

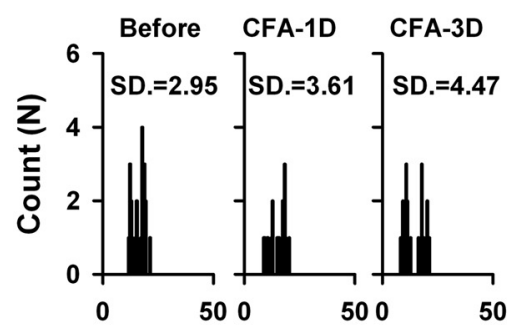

G

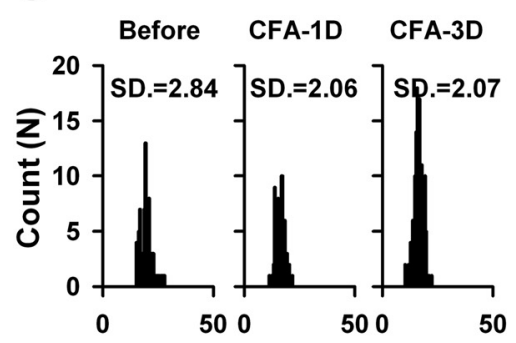

J

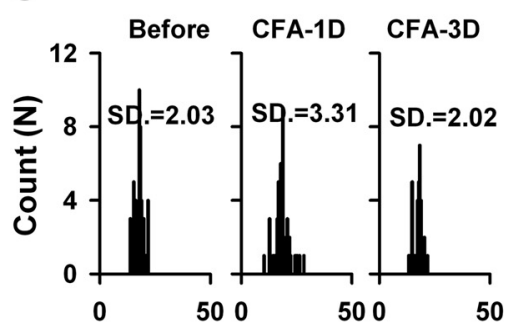

B

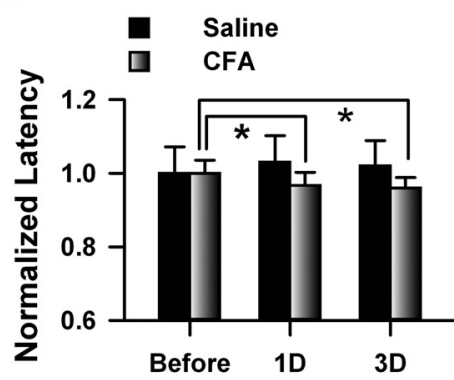

E

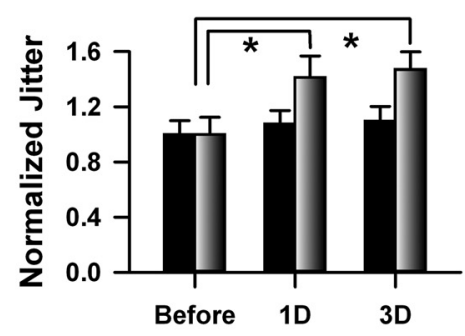

H

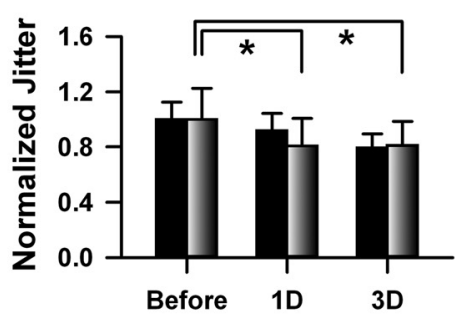

K

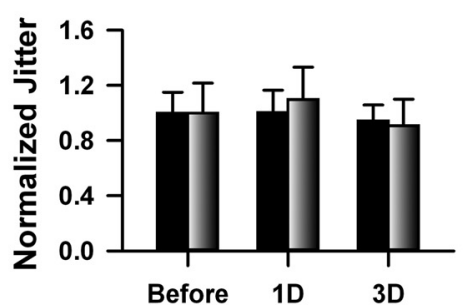

C

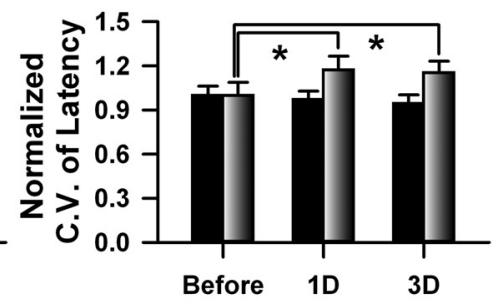

F

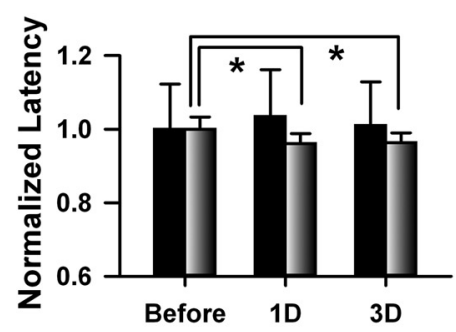

I

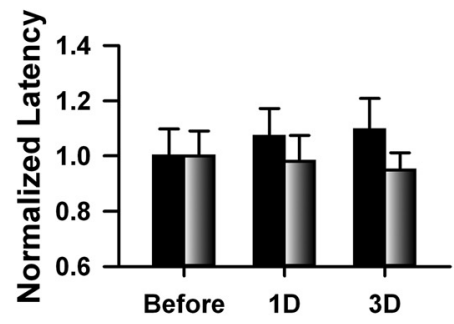

L

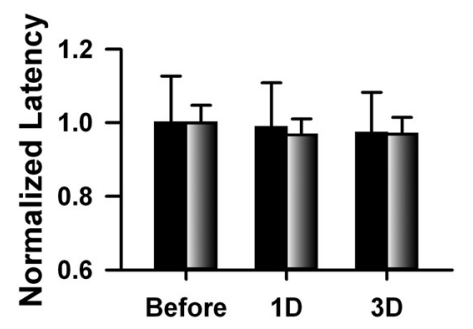

Figure 3. Peripheral inflammation mice by CFA injection changed the temporal properties of spikes firing on cingulate neurons from rats in vivo. Aa, Examples show the original recorded traces in the ACC in response to the stimulations in the thalamus before CFA injection. $\boldsymbol{A} \boldsymbol{b}$, Examples show the original recorded traces of the same neuron as $\boldsymbol{A} \boldsymbol{a}$ in the ACC in response to the stimulations in the thalamus $24 \mathrm{~h}$ after CFA injection. $\boldsymbol{A c}$, The averaged traces recorded before (black) and after (FA injection (gray) were put together to compare the difference of waveform. $\boldsymbol{B}$, Summarized data showed that CFA significantly decreased the latency evoked by thalamic stimulations tested 1 and $3 \mathrm{~d}$ after injection; $n=24$ neurons from four rats for saline group, $n=37$ neurons from seven rats for CFA group. For saline group: saline-1D to before, $t=2.06, p>0.05$; saline-3D to before, $t=1.37, p>0.05$. For CFA group: CFA-1D to before, $t=2.41, p<0.05$; CFA-3D to before, $t=2.93$, $p<0.05 ;{ }^{*} p<0.01$. C, Data show the change of CV of latency of cingulate responses evoked by thalamic stimulations 1 and $3 \mathrm{~d}$ after injection. Data were normalized by the averaged $\mathrm{CV}$ of latency before injection. For saline group: saline-1D to before, $t=0.49, p>0.05$; saline-3D to before, $t=0.95, p>0.05$. For CFA group: CFA-1D to before, $t=3.17, p<0.01$; CFA-3D to before, $t=2.52$, $p<0.05 ;{ }^{*} p<0.05$. D, One example showed that persistent increase of SD of the latency after CFA injection. $\boldsymbol{E}$, Summarized changed jitter of the neurons that persistent increase 1 and $3 \mathrm{~d}$ after CFA injection. For saline group: saline-1D to before, $t=1.24, p>0.05$; saline-3D to before, $t=0.96, p>0.05$. For CFA group: CFA-1D to before, $t=6.48, p<0.01$; CFA-3D to before, $t=6.84$, $p<0.05 ;{ }^{* *} p<0.01$. F, Data from the same group as $\boldsymbol{E}$ shows a decrease of latency tested 1 and $3 \mathrm{~d}$ after injection, For saline group: saline-1D to before, $t=1.88, p>0.05 ;$ saline-3D to before, $t=0.57, p>0.05$. For CFA group: CFA-1D to before, $t=2.87, p<0.01$; CFA-3D to before, $t=2.31, p<0.05 ;{ }^{*} p<0.05$. G, Histogram data show the spikes firing of one neuron, which showed persistent decrease SD of latency after CFA injection. $\boldsymbol{H}$, Bar plot presented the summarized jitter of the group of neurons which has the similar jitter change as $\boldsymbol{G}$. For saline group: saline-1D to before, $t=0.95, p>0.05$; saline-3D to before, $t=2.42, p>0.05$. For CFA group: CFA-1D to before, $t=2.86, p<0.05 ;$ CFA-3D to before, $t=2.44, p<0.05 ;{ }^{*} p<0.05 . I$, The latency from the same group of $\boldsymbol{H}$ was increased by saline injection. For saline group: saline-1D to before, $t=3.61, p<0.05$; saline-3D to before, $t=2.72, p<0.05$. For CFA group: CFA-1D to before, $t=0.24, p>0.05$; CFA-3D to before, $t=0.59, p>0.05 ;{ }^{*} p<0.05$. J, Histogram data showed the spikes firing of one neuron, which showed increased jitter $1 \mathrm{~d}$ but normal jitter $3 \mathrm{~d}$ after injection. $\boldsymbol{K}$, Summarized data showed that the jitter with dynamic change after injection $\boldsymbol{L}$, Bar plot shows the summarized latency of the neurons with dynamic change of jitter. Data in $\boldsymbol{B}, \boldsymbol{F}, \boldsymbol{I}$, and $\boldsymbol{L}$ were normalized by the averaged latency before injection of that group. Data in $\boldsymbol{E}, \boldsymbol{H}$, and $\boldsymbol{K}$ were normalized by the averaged jitter before injection of that group. For the statistics, two-way repeated-measures ANOVA was used and Holm-Sidak method for multiple comparisons. 
$\mathbf{A}_{\mathrm{a}}$

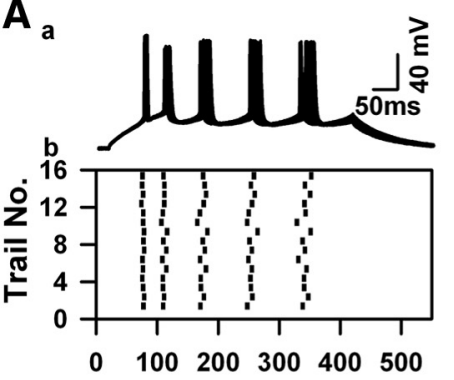

Time (ms)

D

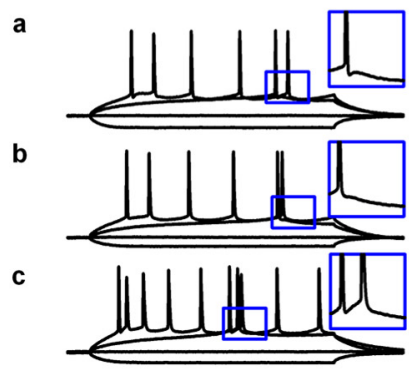

B

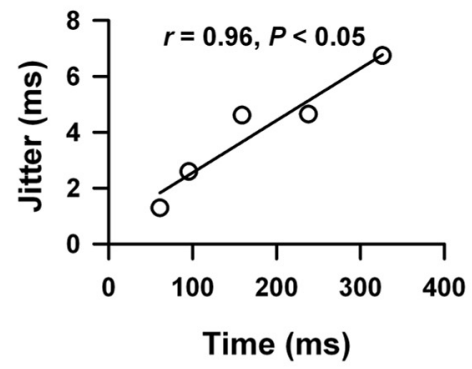

E

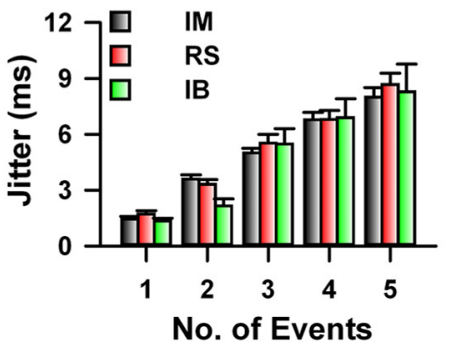

C

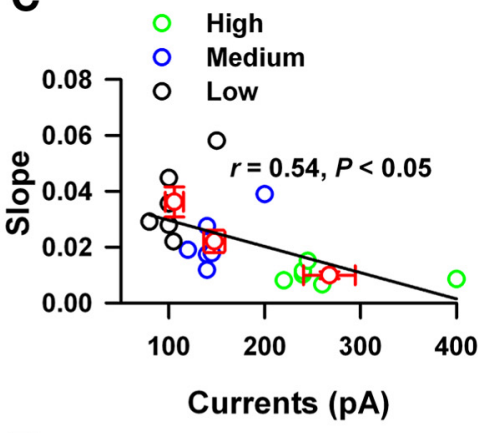

$\mathbf{F}$

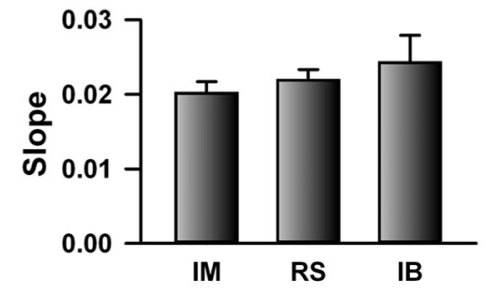

Figure 4. The temporal precision of spikes firing in the ACC of mice in vitro. Aa, The traces showed 15 responses under the steady-state currents stimulations. $A \boldsymbol{b}$, The raster plot showed the AP firing recorded in $\boldsymbol{A a}$. $\boldsymbol{B}$, The jitter and relative time of APs presented in $\boldsymbol{A}$ was fitted by a liner function; the slope indicated the change rate of five total APs. $\boldsymbol{C}$, Represented data showed that the jitter of APs negatively correlated with the amplitude of test currents. Black, blue, and green indicats the slope of jitter change under low, medium, and higher intensity, respectively. Da-DC, Representative examples of firing patterns of intermediate (IM) and regular spiking (RS) neurons respectively. $\boldsymbol{E}$, Summarized data showed that no difference was detected on the total five APs. $\boldsymbol{F}$, The summarized data represent the slope of jitter change of three types of pyramidal neurons. No difference was detected among groups.

\section{CFA inflammation decreased the temporal precision of APs firing in vitro}

To confirm the effects of chronic pain on the temporal precision of AP firing, we performed whole-cell recording on layer II/III of the ACC from mice with saline or CFA injection. As shown in Figure $5 \mathrm{~A}$, CFA injection significantly decreased the paw withdraw threshold of mice tested $1 \mathrm{~d}$ (CFA-1D) or $3 \mathrm{~d}$ (CFA-3D) after injection (saline: $0.50 \pm 0.04 \mathrm{~g}, n=11$, CFA-1D: $0.12 \pm 0.03 \mathrm{~g}, n=8$, CFA-3D: $0.07 \pm$ 0.01 g; one-way ANOVA; $\left.F_{(2,24)}=50.55, p<0.05\right)$. These slices were prepared $45 \mathrm{~min}$ after behavioral testing. Figure $5 B, C$ shows one example of the temporal precision of AP firing from mice with saline or CFA injection, respectively. CFA significantly increased the slope of jitter change on both 1 and 3 day after injection (saline: $0.021 \pm$ 0.001, $n=29$, CFA-1D: $0.030 \pm 0.002, n=21$, CFA-3D: $0.037 \pm$ $0.005, n=11$, one-way ANOVA on Ranks, $H=11.84, p<0.01$; Fig. $5 D$ ), whereas the jitter of first APs from CFA-1D was bigger than the saline and CFA-3D group (saline: $1.51 \pm 0.10, n=29$, CFA-1D: $2.04 \pm 0.18, n=21$, CFA-3D: $1.53 \pm 0.14, n=11$, one-way ANOVA, $\left.F_{(2,60)}=4.39, p<0.05\right)$. Significant difference was also detected on the jitter of total five APs (two-way ANOVA, $F_{(2,304)}=$ 21.47, $p<0.001$; Fig. $5 E$ ). Our data indicate that the jitter of APs firing in the ACC was significantly increased in both 1 and $3 \mathrm{~d}$ after CFA injection.

We further investigated the temporal precision of APs firing evoked by a sEPSCs (Rodriguez-Molina et al., 2007). As shown in Figure $5 F$, the sEPSCs with different rise and decay time $(\tau R / \tau \mathrm{D}$ : $0.3 / 3$ or $1 / 10$ ) were injected at an amplitude level which could just elicited APs. The jitter from a mouse one day after CFA injection elicited by slower sEPSCs stimulation $(\tau \mathrm{R} / \tau \mathrm{D}, 1 / 10)$ was significantly higher than the control group (saline: $0.97 \pm 0.12 \mathrm{~ms}, n=$ 6, CFA-1D: $1.5 \pm 0.23 \mathrm{~ms}, n=6, t$ test, $p<0.05$; Fig. $5 G$ ), whereas faster sEPSCs stimulations $(\mathrm{R} / \tau \mathrm{D}: 0.3 / 3)$ did not show the same effect (saline: $0.64 \pm 0.11 \mathrm{~ms}, n=6$; CFA-1D: $0.53 \pm$ $0.11 \mathrm{~ms}, n=6$, $t$ test, $p>0.05$; Fig. $5 G$ ).

\section{Nerve injury also decreased the temporal precision of AP firing in vitro}

To see whether this finding can be extended to nerve injury, we used a neuropathic pain model to evaluate the effects of peripheral nerve injury on the temporal precision of information coding. One week after the CPN ligation, mice with decreased paw withdraw threshold were used for the electrophysiology recording. Similar as the results from CFA-injected mice, peripheral nerve injury significantly increased the slope of jitter change (control: $0.020 \pm 0.002, n=10$; nerve injury: $0.033 \pm 0.003, n=$ 15 ; $t$ test, $p<0.01$; Fig. $5 H$ ), and the jitter of total five APs (two-way ANOVA; $F_{(1,124)}=19.66, p<0.001$; Fig. 5I). However, the nerve injury did not change the jitter of first AP in our recording system (control: $1.69 \pm 0.21, n=10$; nerve injury: $1.81 \pm$ $0.17, n=15, t$ test, $p>0.05$; Fig. $5 H)$.

\section{Synaptic strength contributes to the modulation of jitter} Different factors have been shown to affect the temporal precision of APs firing, including synaptic transmission and the stochastic activities of ion channels (Tiesinga et al., 2008). Previous studies show that glutamate release in the ACC was enhanced by CFA injection (Zhao et al., 2006), which may be involved in the change of temporal precision induced by CFA. To investigate this possibility, we blocked the major components of both excitatory and inhibitory synaptic transmission by applying a mixture of 6-cyano-7-nitroquinoxalone-2,3-dione (CNQX; $25 \mu \mathrm{M}$ ), 2-amino5-phosphonopentanoate (AP5; $50 \mu \mathrm{M})$, and picrotoxin $(100 \mu \mathrm{M})$. 
A

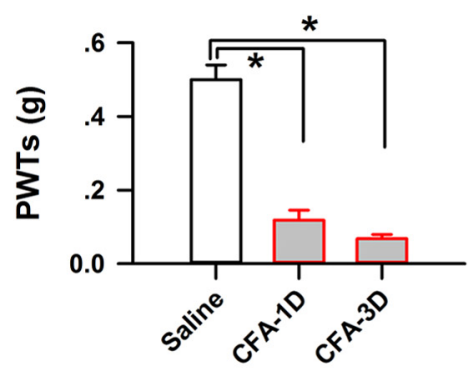

B

D

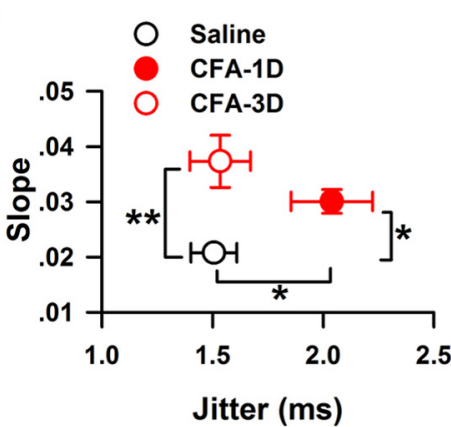

G

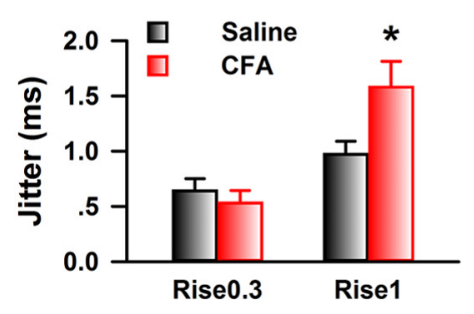

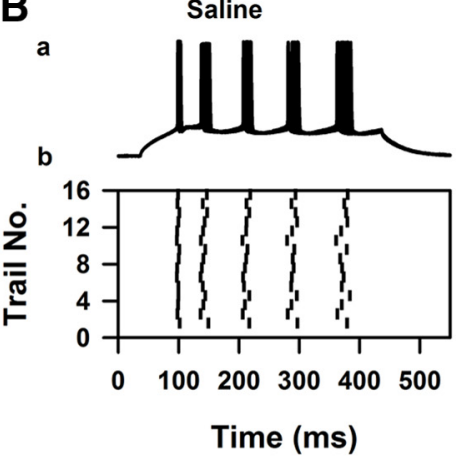

Time (ms)

E

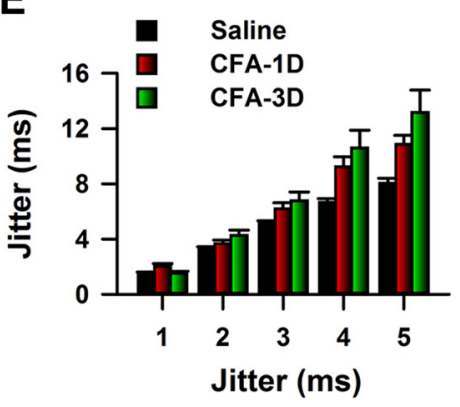

H

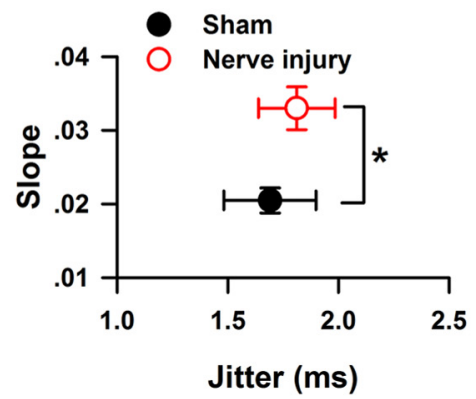

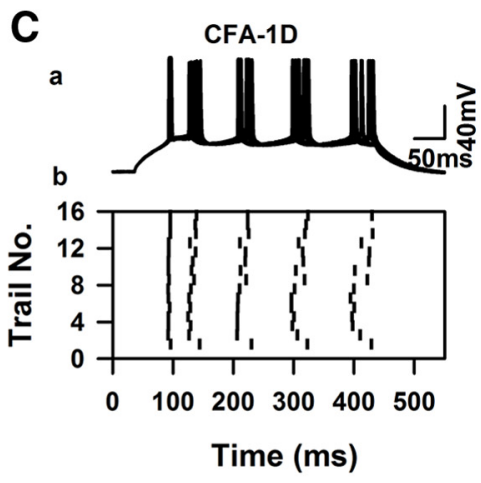

F

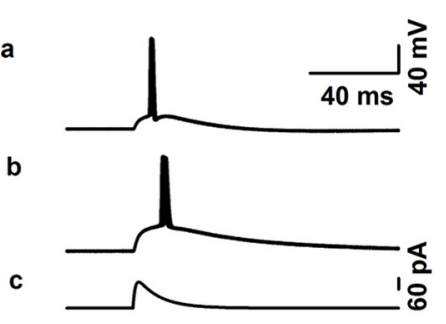

I

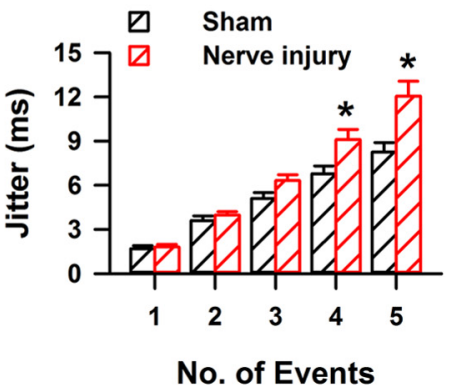

Figure 5. Inflammation of mice decreased the temporal precision of AP firing of neurons in the ACC of mice in vitro. $\boldsymbol{A}$, CFA significantly decreased the paws withdraw threshold of mice on 1 and $3 \mathrm{~d}$ after injection. $\mathbf{B a}$, The traces showed 15 responses under the steady-state currents stimulations recorded in the ACC from control mice. $\boldsymbol{B} \boldsymbol{b}$, The raster plot showed the APs recorded in $\mathbf{A} \boldsymbol{a}$. $\boldsymbol{C} \boldsymbol{a}$, The traces showed 15 responses under the steady-state currents stimulations recorded in the ACC from CFA-injected mice (CFA-1D). C $b$, The raster plot showed the APs recorded in Ba. $\boldsymbol{D}$, Significant differences were detected in the jitter of the first AP and the slope of jitter between saline (opened black circle) and (FA-1D (filled red circle), CFA-3D group (open red circle); ${ }^{*} p<0.05 . E$, The jitter of AP firing from saline-injected mice (black bar) was significantly different from (FA-injected mice (red bar for CFA-1D, green bar for CFA-3D; tw0-way AN0VA; ${ }^{*}<<0.05$ ). Fa, Represented 15 traces elicited by simulated EPSCs ( $\tau$ rise/ $\tau$ decay:0.3/3 ms). Fb, Represented 15 traces elicited by simulated EPSCs ( $\tau$ rise/ $\tau$ decay: $1 / 10 \mathrm{~ms}$ ). Fc, Represented the simulated EPSCs ( $\tau$ rise/ $\tau$ decay: $1 / 10 \mathrm{~ms}$ ) generated by function $/(t)=\lambda[\exp (-t / \tau$ decay $)-\exp (-t / \tau$ rise $)]$ (see Materials and Methods). $\mathbf{G}$, The summarized data showed the jitter of AP firing evoked by simulated EPSC $\mathrm{s}$ with different rise and decay time (rise/decay: $0.3 / 3$ or $1 / 10 \mathrm{~ms}$ ). The jitter of latency from CFA-injected mice was higher than the control with the stimulations of simulated EPSCs with rise/decay: $1 / 10$. "* , $p<$ 0.05. $\boldsymbol{H}$, CPN ligation significantly increased the slope of jitter change tested 1 week after surgery; $t$ test, $p<0.05$. I, Summarized data presented the jitter change induced by CPN ligation.

Interesting, for the CFA-injected mice, bath application of the mixture solution decreased the jitter of both first APs (mixture CFA-1D: $1.17 \pm 0.18, n=8$; test $\mathrm{U}, p<0.01$; Fig. $6 A$ ) and the total five APs (two-way ANOVA; $F_{(1,154)}=6.48, p<0.05$; Fig. $6 A)$. However, the same application had no effect on the jitter of AP firing of control mice (two-way ANOVA; $F_{(1,148)}=2.36, p>$ 0.05 ; Fig. 6A). Similar effects were observed with the sEPSCs stimulations $(\tau \mathrm{R} / \tau \mathrm{D}, 1 / 10$ : saline: $1.27 \pm 0.30 \mathrm{~ms}, n=5$; CFA: $1.12 \pm 0.14, n=7, t$ test, $p>0.05$; Fig. $6 B$ ). Furthermore, the application of mixture solution eliminated the jitter difference of both the slope (control: $0.025 \pm 0.003, n=12$; nerve injury: $0.022 \pm 0.002, n=12, t$ test, $p>0.05$ ) and total five APs (twoway ANOVA; $F_{(1,119)}=0.14, p>0.05$; Fig. $6 C$ ) between control and nerve injury group. Therefore, our data suggest that the syn- aptic transmission was involved in the change of temporal precision of APs firing in the ACC after CFA inflammation.

To confirm this point, we further analyzed the basic properties of APs without mixture application, the input-output curve of APs firing from CFA-injected mice was similar as that from normal mice (two-way ANOVA; $F_{(1,423)}=3.51, p>0.05$; Fig. $6 D)$. Furthermore, the Rheobase which can just induced APs bursting (saline: $91.25 \pm 5.11 \mathrm{pA}, n=29$; CFA: $81.43 \pm$ $5.96 \mathrm{pA}, n=21, t$ test, $p>0.05$; Fig. $6 E$ ), and the test currents (saline: $155.00 \pm 7.03 \mathrm{pA}, n=29$; CFA: $142.38 \pm 9.07 \mathrm{pA}, n=$ $21, t$ test, $p>0.05$; Fig. $6 E$ ) were also similar between the saline- and CFA-injected group, suggesting that the neuronal intrinsic properties may not be involved in the decrease of temporal precision. 
A

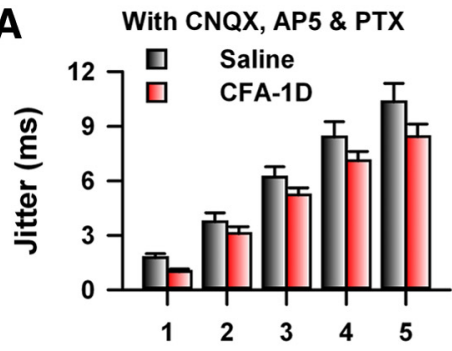

No. of Events

D

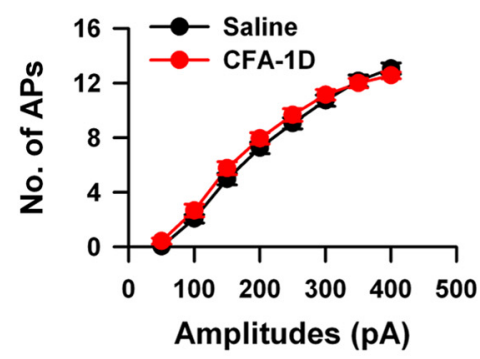

G

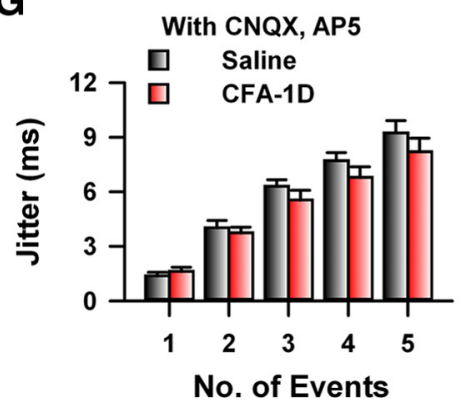

B

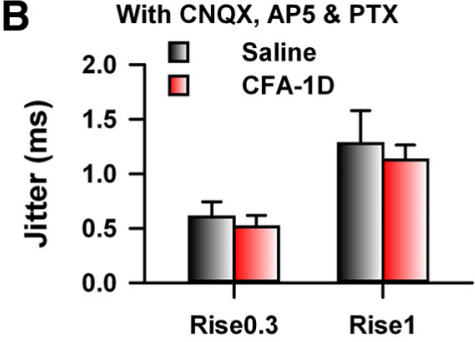

E

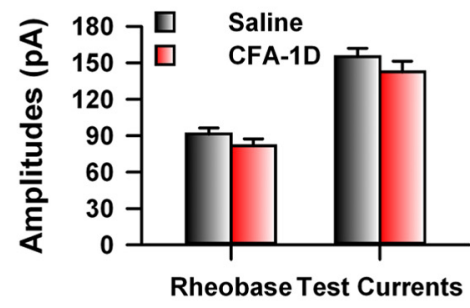

H

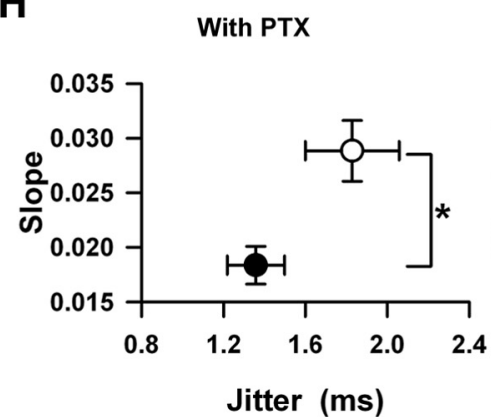

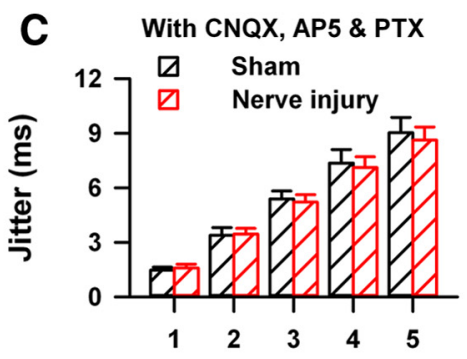

No. of Events

F

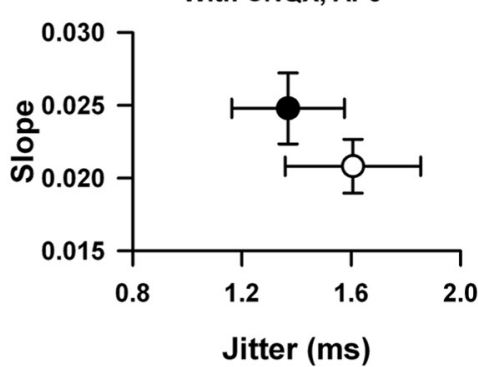

I

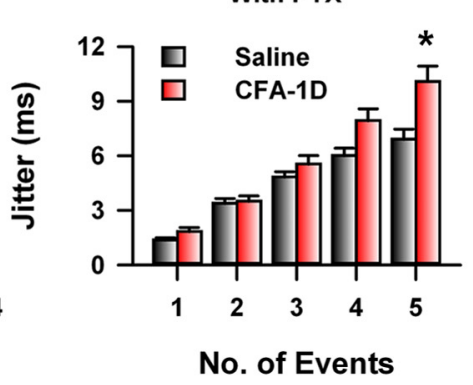

Figure 6. Glutamatergic instead of GABAergic synaptic transmission was involved in the change of temporal precision of AP firing induced by CFA injection. $\boldsymbol{A}$, The application of mixture with CNQX $(25 \mu \mathrm{M}), \operatorname{AP5}(50 \mu \mathrm{M})$, and picrotoxin $(100 \mu \mathrm{M})$ decreased the jitter of AP firing in CFA-injected mice, but not the control mice. $\boldsymbol{B}$, The mixture application abolished the difference of jitter elicited by simulated EPSCs; $p<0.05$. C, Blocking of the synaptic transmission eliminated the change of jitter induced by nerve injury. $\boldsymbol{D}$, Summarized data showed the functions of currents intensity and number of APs of neurons in the ACC from control and CFA-injected mice. $E$, No difference was detected on the rheobase and test currents, which was used to examine the jitter between control and CFA group. $F$, Blocking glutamatergic synaptic transmission by $C N Q X(20 \mu \mathrm{M})$ and AP5 $(50 \mu \mathrm{M})$ in bath solution decreased the slope of jitter in CFA-injected mice, therefore abolished the difference between control (black) and CFA group (red). G, Blocking glutamatergic synaptic transmission by CNQX ( $25 \mu \mathrm{M}$ ) and AP5 (50 $\mu$ ) in bath solution abolished the difference of jitter between control and CFA group. $\boldsymbol{H}$, Bath application of picrotoxin $(100 \mu \mathrm{M})$ did not abolish the difference of slope of jitter between control and CFA group $(t$ test, $p<0.01)$. $I$, Bath application of picrotoxin $(100 \mu \mathrm{M})$ did not abolish the difference of slope of jitter between control and (FA group (two-way ANOVA, $p<0.01$ ).

Glutamatergic but not GABAergic transmission was involved in the change of jitter

To test whether the glutamatergic or GABAergic synaptic transmission was involved in the change of temporal precision induced by CFA, we first bath applied a mixture of CNQX (25 $\mu \mathrm{M})$ and AP5 (50 $\mu \mathrm{M})$ to block the glutamatergic synaptic transmission, similar as our previous observation, blocking of glutamatergic synaptic transmission decreased the jitter of AP firing for the five total APs of CFAinjected mice (two-way ANOVA; $F_{(1,154)}=6.5, p<0.05$; Fig. $6 F$ ) but not the jitter of control mice (two-way ANOVA; $F_{(1,139)}=3.12$, $p>0.05$; Fig. $6 F, G)$, therefore application of mixture (CNQX + AP5) abolished the difference between saline- and CFA-injected mice (two-way ANOVA; $F_{(1,94)}=1.49, p>0.05$; Fig. $6 F, G$ ). Furthermore, bath applying of picrotoxin alone, which blocked the activities of $\mathrm{GABA}_{\mathrm{A}}$ receptors, did not abolish the difference of jitter between saline- and CFA-injected mice (saline: $n=11$, CFA-1D, $n=13$; two-way ANOVA; $F_{(1,119)}=16.04$, $p<0.01$; Fig. $6 H, I)$. These results suggest that the glutama- tergic, but not GABAergic synaptic transmission was involved in the jitter change under chronic pain.

To confirm whether spontaneous EPSPs affect the temporal precision of APs, we analyzed the number and relative time of spontaneous EPSPs $100 \mathrm{~ms}$ ahead of the onset of sEPSCs (Fig. $7 A)$. Spontaneous EPSPs were detected from five of six neurons of each group, the jitter of the APs elicited by stimulated EPSCs positively correlated with the number of spontaneous EPSPs $(r=0.69, p<0.05$; Fig. $7 B)$. The recorded APs of individual neurons were further separated into two groups based on whether spontaneous EPSPs were detected; jitter and mean latency of the APs were then recalculated. As shown in Figure $7 C$, excepting the affected APs increased the latency (with spontaneous EPSPs: $18.41 \pm 0.28 \mathrm{~ms}$; no spontaneous EPSPs: $19.22 \pm 0.36 \mathrm{~ms}, n=5$; paired $t$ test, $p<0.01$; Fig. $7 C$ ) but decreased jitter of APs firing in the CFA-injected group (no spontaneous EPSPs: $1.28 \pm 0.15 \mathrm{~ms}, n=5$, paired $t$ test, $p<$ 0.05; Fig. 7D), and abolished the difference of jitter between 
A

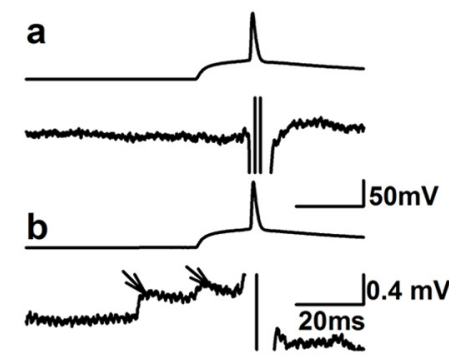

B
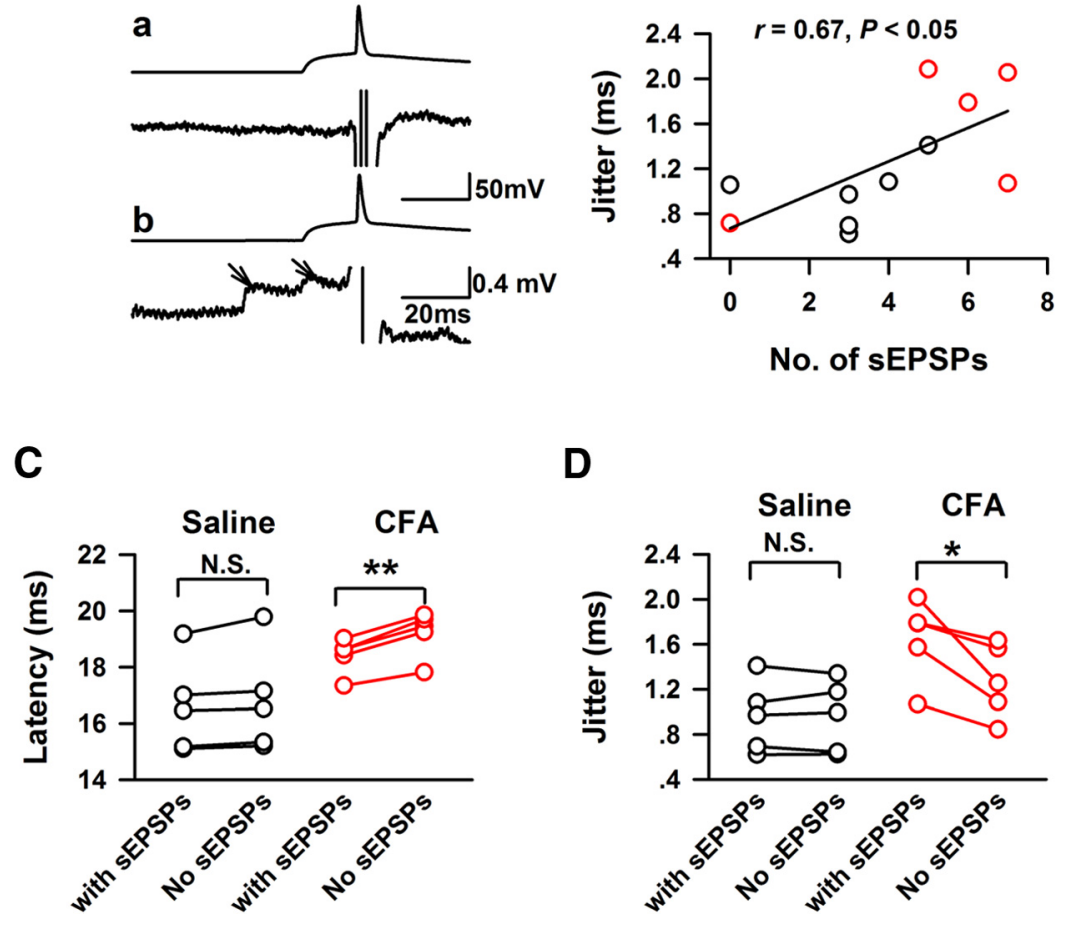

Figure 7. The number and relative time of spontaneous EPSPs $100 \mathrm{~ms}$ ahead of simulated EPSCs correlated with the jitter change induced by CFA. $\boldsymbol{A}$, Examples showed the detection of spontaneous EPSPs in the recorded traces. $\boldsymbol{A a}$, Top, The recorded traces elicited by simulated EPSCS. Bottom, The traces after the subtraction of averaged recorded traces, no spontaneous EPSCs was detected in this recorded response. $\boldsymbol{A} \boldsymbol{b}$, One example that spontaneous EPSCs were detected in the recorded response, the arrows in lower part indicated two sEPSCS. $\boldsymbol{B}$, The jitter of AP firing was positively correlated with the number of spontaneous EPSPs in the ACC. C, The presentations of spontaneous EPSPs changed the latency of APs firing in CFA-injected mice; n.s. $=p>0.05 ;{ }^{* *} p<$ 0.01. D, The presentations of spontaneous EPSPs increased the jitter of APs firing in CFA-injected mice $n . s .=p>0.05,{ }^{*} p<0.05$.

control and CFA-injected group ( $t$ test, $p>0.05)$. Our data therefore suggest that the number and relative time of spontaneous EPSPs affect the temporal precision of AP firing in chronic pain conditions.

\section{The temporal effects of synaptic events on the firing time of APs}

To further investigate how the spontaneous EPSCs affect the temporal precision of AP firing, we induced evoked minimal EPSPs (eEPSPs) by placing stimulation electrode in layer $\mathrm{V}$ of the ACC to mimic the spontaneous synaptic events (Fig. $8 A, B$ ). The amplitudes of eEPSPs (saline: $1.03 \pm 0.13 \mathrm{mV}$; CFA: $2.24 \pm 0.27 \mathrm{mV}$, $n=5$ for each group) was 2 - to 3 -fold of the amplitudes of spontaneous EPSPs (saline: $0.48 \pm 0.05 \mathrm{mV}$; CFA: $0.65 \pm 0.08$ $\mathrm{mV}, n=5$ for each group; Fig. $8 C$ ). The eEPSPs were induced at different time points and the change of the AP firing elicited by simulated EPSCs (rise/decay: 1/10 ms) were examined. When eEPSPs were presented ahead of the onset of simulated EPSCs, the time difference between two stimulations were treated as minus. Figure $8 A$ shows one example from saline group, the mean latency of the simulated EPSC elicited response was $8.6 \mathrm{~ms}$, when the electrical stimulations were applied 15.0 and $36.0 \mathrm{~ms}$ ahead, the mean latency became to 7.1 and $7.6 \mathrm{~ms}$. Similar effects were observed in the CFA-injected group (Fig. 8B). As shown in Figure $8 D$, the presentations of eEPSPs shorted the latency of AP firing on both saline- and CFA-injected mice, and the effects was different between control and CFA-injected group (two-way ANOVA, $F_{(1,79)}=6.37, p<0.05$; Fig. $\left.8 D\right)$. The biggest effects happened when eEPSPs were presented $4.4 \mathrm{~ms}$ ahead of sEPSCs for saline, and $25.5 \mathrm{~ms}$ ahead of sEPSCs for CFA group.

\section{The predication of the temporal characteristics of spikes firing}

Because the relative time of electrical stimulation to the onset of simulated EPSCs included the latency of eEPSCs, we further calibrated the relative time of eEPSPs to sEPSCs by subtracting the latency. The effects of eEPSPs on the firing latency of APs were then fitted with a Gaussian function. As shown in Figure $8 E$, the Gaussian function fitted the effects of eEPSPs on the latency of APs very well (saline: $r=0.84, p<0.05$; CFA: $r=0.90$, $p<0.05)$. We then used the starting time of sEPSPs to predict the latency of APs by using the fitted function and the jitter of latency were further predicted based on the mean latency of APs without sEPSPs. Figure $8 F$ shows the predicted jitter and latency of AP firing in both saline- and CFA-injected groups by using the relative time of sEPSPs and Gaussian function (jitter: saline $1.05 \pm 0.12 \mathrm{~ms}$, CFA: $1.57 \pm$ $0.09 \mathrm{~ms}, t$ test, $p<0.05$; latency: saline $16.47 \pm 0.78 \mathrm{~ms}, \mathrm{CFA}: 18.34 \pm 0.38 \mathrm{~ms}$; Fig. $8 F, G)$. The predict deviation for the jitter or latency was $\sim 10 \%$ or $1 \%$ in both saline- and CFA-injected groups, respectively (jitter: saline $17.19 \pm 8.82 \%$, CFA $9.98 \pm 2.88 \%$; latency: saline $1.02 \pm$ $0.35 \%$, CFA $1.57 \pm 0.23 \%$ ).

\section{cAMP signaling pathway was involved in the temporal} precision change induced by CFA

Previous studies have shown that cAMP signaling pathway was involved in the regulation of chronic pain (Wei et al., 2002; Wang et al., 2011). To investigate whether cAMP signaling pathway is involved in the change of temporal precision of AP firing in chronic pain conditions, we compared the jitter of AP firing of saline- or CFA-injected AC1 knock-out mice (KO). Interesting, CFA injection has no effect on the jitter of AP firing of $A C 1 \mathrm{KO}$ mice (AC1 KO, saline: $n=13$, CFA-1D: $n=9$, two-way ANOVA; $F_{(1,109)}=0.05, p>0.05$; Fig. $\left.9 A\right)$, bath application of a selective ACs activator forskolin $(20 \mu \mathrm{M})$ significantly increased the jitter of AP firing of normal mice (control: $n=7$, forskolin, $n=6$, two-way ANOVA; $F_{(1,64)}=38.31, p<0.01$; Fig. 9B). Consistent with previous observations, blocking the synaptic transmission by mixture of CNQX, AP5 and picrotoxin abolished the effects of forskolin on jitter (mixture: $n=5$, compared with control: twoway ANOVA; $F_{(1,59)}=3.96, p>0.05$; Fig. $\left.9 B, C\right)$. Therefore, our data suggest that CAMP signaling pathway was involved in the temporal precision of information coding by the modulation of synaptic transmission.

\section{Discussion}

The temporal change of information coding induced by peripheral inflammation

The temporal properties of information coding along the sensory pathway were changed under chronic pain conditions. In the 
A
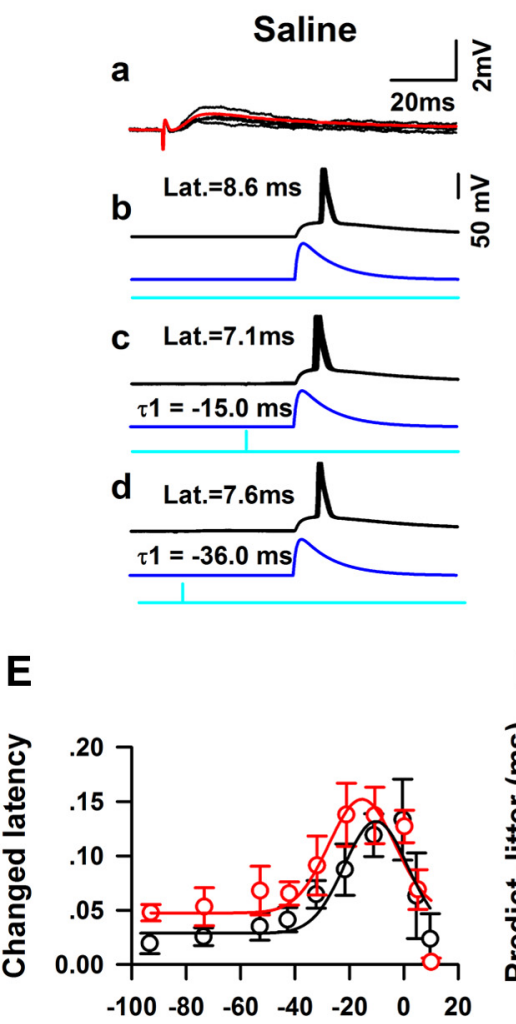

Time (ms)
B
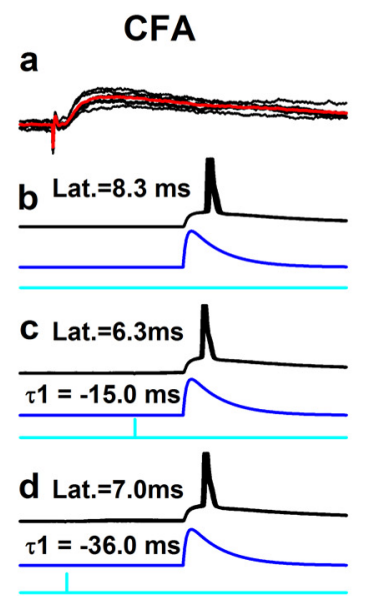

F G

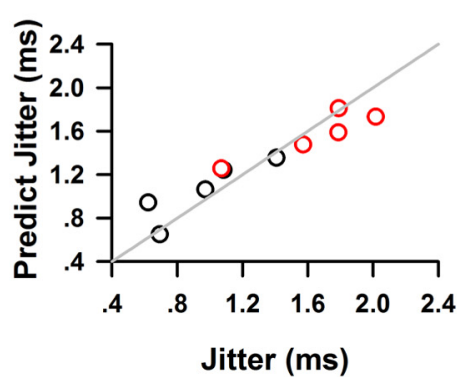

C
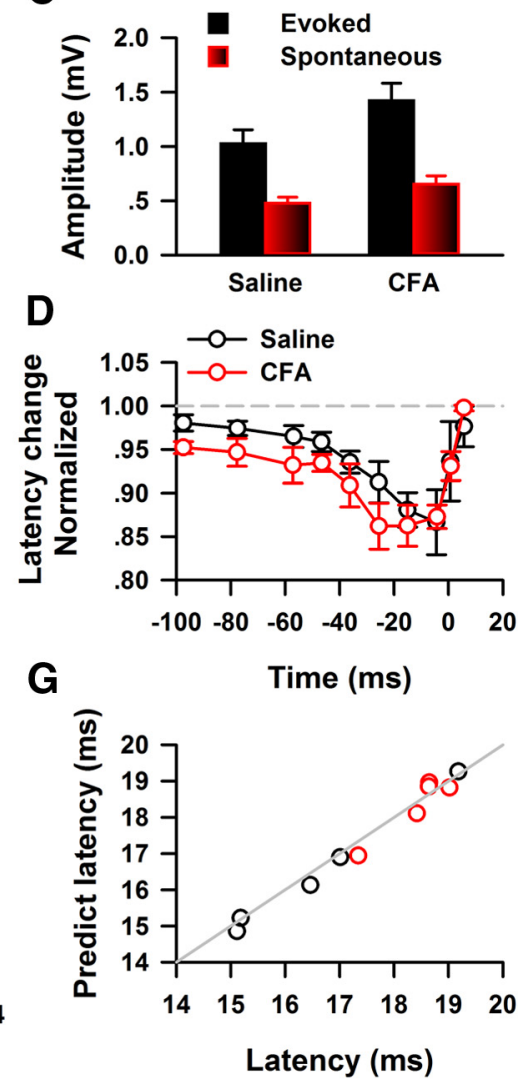

Figure 8. Evoked mini-EPSPs shorted the latency of APs when presented ahead of the onset of sEPSPs. Aa, Representative examples of traces of EPSPs evoked by electrical stimulation of layers II-III of ACC, the averaged response trace is shown in red. $\boldsymbol{A} \boldsymbol{b}$, Five traces of APs firing under simulated EPSC stimulation. Ac, Five traces of APs firing under simulated EPSC stimulation combining an electrical stimulation applied $15.0 \mathrm{~ms}$ ahead the onset of sEPSCs. Ad, Five traces of APs firing under the combined simulated EPSCs and electrical stimulation with - 36.0 ms time difference. The blue line in $\boldsymbol{A} \boldsymbol{b}$ - $\boldsymbol{A d}$ shows the waveform of simulated EPSCs. The cyan line in $\boldsymbol{A} \boldsymbol{b}-\boldsymbol{A d}$ shows the presentation of electrical stimulation. $\boldsymbol{B}$, The responses of APS under the stimulations of a combination of simulated EPSCs and electrical stimulations. The subsets of $\boldsymbol{B} \boldsymbol{b}-\boldsymbol{B} \boldsymbol{d}$ represented the same contents as in $\boldsymbol{A} \boldsymbol{b}-\boldsymbol{A d \boldsymbol { d }}$. $\boldsymbol{C}$, Summarized data show the amplitudes of eEPSPs and sEPSPs in both the control and CFA-injected groups. D, Pooled data show the eEPSPs had bigger effect on the latency of APs firing elicited by sEPSCs in CFA-injected mice (tw0-way ANOVA, $p<0.05$ ). $\boldsymbol{E}$, The relative of time eEPSPs (calibrated by latency of eEPSCs) to the onset of sEPSCs affect the latency of APs firing. The summarized data from control (open black circle) or CFA-injected group (open red circle) was fitted by a Gaussian function, respectively. $\boldsymbol{F}$, The relative time of SEPSPs predicted the jitter of APs firing by using the Gaussian function in $\boldsymbol{E}$. Gray line indicats $100 \%$ prediction. $\boldsymbol{G}$, The relative time of $\mathbf{E P S P}$ S predicted the latency of AP firing using the Gaussian function in $\boldsymbol{E}$.

A

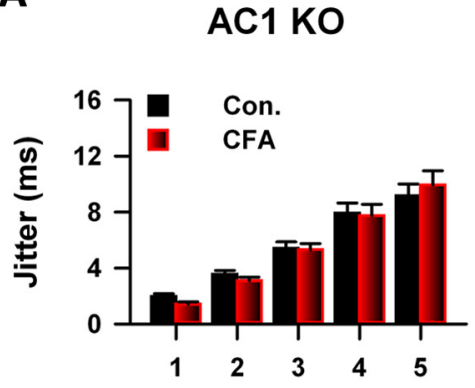

No. of event
B

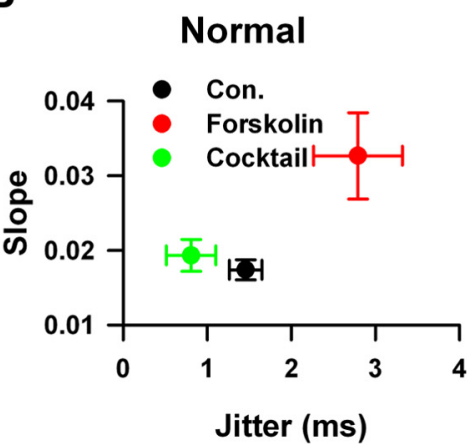

C

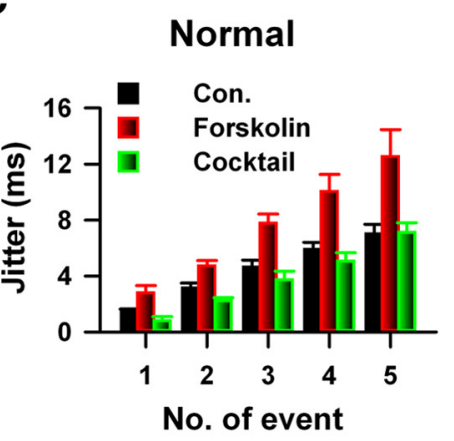

Figure 9. CAMP signaling pathway was involved in the change of temporal precision of AP firing of neurons in the ACC in vitro. $A$, CFA injection did not change the temporal precision of APs firing in the ACC of AC1 KO mice. $B$, Bath application of forskolin increased the slope of jitter in normal mice, blocking of the activities of both excitatory and inhibitory receptors abolished the increase. $\boldsymbol{C}$, Activating of the cAMP signaling pathway by forskolin application increased the jitter of APs, which depends on the synaptic transmission.

peripheral nervous system, injured afferent axons or associated cell bodies generated ectopic discharge spontaneously, which may contribute to chronic pain by triggering the central sensitization (Devor, 1991, 2006, 2009; Amir et al., 1999, 2005; Han et al., 2000; Kovalsky et al., 2009), similar phenomenon have been reported in the spinal cord (Harvey et al., 2006), thalamus (Lenz et al., 1987, 1998), primary motor cortex (Múnera et al., 2012), and cingulate cortex (Gao et al., 2006). Furthermore, Biella et al. (1999) reported that the peripheral nerve injury changed temporal sequences of neuronal discharges with different noxious and non-noxious stimuli. However, whether the temporal precision of AP firing was changed in chronic pain conditions has not been 
previously studied. In the present study, by an in vivo extracellular recording approach, we found that the temporal characteristics of the APs firing in the thalamic-cingulate pathway were changed under inflammatory pain condition, including decreased latency and temporal precision of spikes firing. In our recording system, $51 \%$ of neurons showed increased jitter, whereas $24 \%$ showed decreased jitter persistently, and 25\% neurons showed dynamic change. By using brain slices, we observed an increased jitter of APs firing in the ACC on both 1 and $3 \mathrm{~d}$ after CFA injection. Furthermore, similar jitter change was observed from mice with nerve ligation for 1 week. Therefore, by using both inflammatory pain and neuropathic pain model, for the first time we reported that the temporal precision of information coding within thalamic-cingulate pathway was decreased under chronic pain conditions.

\section{Spontaneous synaptic noise affects the temporal precision of information coding}

Different factors affect the variability of spikes firing in the CNS (Faisal et al., 2008). The firing of APs was affected by the fluctuations of membrane potentials (Bean, 2007). The opening or closing of intrinsic currents, such as sodium or potassium channels, and synaptic noise are major factors which affect the variance of AP firing (Faisal et al., 2008, Tiesinga et al., 2008). Here we observed that blocking of glutamatergic synaptic transmission abolished the jitter change in chronic pain conditions. And the jitter of APs correlated with the number of sEPSPs $100 \mathrm{~ms}$ ahead of onset of simulated EPSPs, this was consistent with previous studies that the release probability of glutamate in the ACC was increased in chronic pain conditions (Zhao et al., 2006), which lead to bigger changes of the membrane potentials, and further increased the variability of AP firing (Yu et al., 2011).

The synaptic noises are one of the major factors that affect the temporal precision of spikes firing (Mainen and Sejnowski, 1995; Faisal et al., 2008; Tiesinga et al., 2008). The input of synaptic conductance changed the fluctuations of membrane potentials, therefore change the variability of AP firing (Zsiros and Hestrin, 2005). Ariav et al. (2003) found that the integration of synaptic noise and dendritic spikes regulates the precision of outputs of pyramidal neurons in CA1. Fricker and Miles (2000) show that the prolonged EPSPs varied AP firing time in the pyramidal neurons in CA1. The involvements of AMPA and NMDA receptors to the temporal precision of AP firing have been investigated in the cortex (Harsch and Robinson, 2000) and cerebellum (Cathala et al., 2003). We combined eEPSPs and sEPSCs and studied the temporal effects of eEPSP to AP firing. We found that the presentation of eEPSPs shorted the latency of AP firing following a Gaussian function. The relative time of the spontaneous EPSPs to the onset of sEPSCs could be used to predict the latency and jitter of AP firing. Our data suggest that the effects of synaptic noise on the firing time of APs follow the temporal summation principle of dendrites (Stuart and Hausser, 2001). Significant difference was detected between control and CFA when the eEPSPs were ahead of the onset of sEPSCs, suggesting that the dendritic temporal summation properties may be changed by chronic pain. In total, our data suggest that the temporal summation of the synaptic transmission may be changed by the CFA injection in the ACC.

The activities of intrinsic currents may be involved in the temporal precision of AP firing. Vervaeke et al. (2006) reported that $\mathrm{I}_{\mathrm{NaP}}$ in CA1 decreased temporal precision of AP firing in response to single EPSPs, and $\mathrm{I}_{\mathrm{NaP}}$ was involved in chronic epilepsy by the modulation of temporal precision of AP firing in the dentate gyrus (Epsztein et al., 2010). The activities of potassium channels regulate the firing time of APs. In interneurons, suppressing outward potassium currents increased the variability of latency of synaptically induced AP firing (Fricker and Miles, 2000), and homostatic downregulation of dendrotoxin-sensitive D-type $\mathrm{K}$-current increased the precision of AP generation in CA3 pyramidal neurons (Cudmore et al., 2010). Our observations that CFA did not change the rheobase, resting membrane potentials, and testing currents of cingulate pyramidal neurons, suggest that the intrinsic properties are not involved in the decrease of temporal precision in chronic pain conditions, but it may regulate the difference of jitter between the first AP and fifth AP under the steady-state currents stimulation. The involvements of intrinsic currents to the temporal properties of AP firing in the cingulate cortex need to be further studied.

\section{The involvement of cAMP signaling pathway to chronic pain} cAMP signaling pathway was involved in chronic pain. Previous studies found that the deficits of AC1 and/or AC8 abolished the developments of chronic pain (Wei et al., 2002; Zhao et al., 2006). A specific inhibitor of AC1 has been shown to have potent analgesic effects on chronic pain mouse model (Wang et al., 2011). Here we showed that cAMP signaling pathway was involved in the change of temporal precision of AP firing in chronic pain conditions via synaptic transmission, because the jitter increase was abolished in AC1 knock-out mice, and activation of AC1 by forskolin decreased the temporal precision of APs in normal mice and elimination of synaptic transmission blocked the effects of forskolin. The involvements of AC1 to chronic pain were mediated by both presynaptic and postsynaptic mechanisms (Zhuo, 2008). In the postsynapses, the activation of AC1 may lead transcription or protein translational effect, whereas in the presynapses, cAMP signaling pathway may regulate glutamate release (Zhao et al., 2006). Here we found that in the ACC, cAMP signaling pathway modulated the temporal characteristics of spikes firing under chronic pain conditions.

\section{The possible mechanism mediating the effects of chronic pain on cognition}

The temporal properties of information coding in the thalamusprefrontal cortex connection is important to the regulation of cognition. The mPFC was involved in the regulation of both recent (Descalzi et al., 2012) and remote memory (Frankland and Bontempi, 2005). The connections between media-dorsal nucleus and prefrontal cortex are necessary for the cognition. The $\beta$-range synchrony in the MD-PFC is enhanced during acquisition and performance of a working memory task, whereas inhibition of the MD activities disrupted the synchrony and impaired the working memory (Parnaudeau et al., 2013). A further study showed that the chronic pain suffering impaired spatial memory combined with a reduced MD-PFC connectivity (Cardoso-Cruz et al., 2013b). Here we showed that the temporal precision of information coding in the MD-PFC is decreased in chronic pain conditions. This temporal precision change may affect the activity dependent dynamic modulation of synaptic transmission in the MD-PFC pathway, because the regulation of synaptic transmission in the ACC is highly dependent on the temporal properties of induction protocols. For example, it was found that $1 \mathrm{~Hz}$ stimulation for $15 \mathrm{~min}$ induced long-term depression, whereas high-frequency stimulation leads to long-term potentiation of synaptic transmission, and also the sequence of the AP firing of presynaptic and postsynaptic neurons could also change the strength of synaptic transmission (Zhao et al., 2005). Further- 
more, the decrease of temporal precision may change the synchronous firing within population neurons, which affect the generation and traveling of oscillation (Rutishauser et al., 2010). Further studies need to be performed to investigate how the temporal precision of information coding is involved in the regulation of cognitions in chronic pain conditions.

\section{References}

Amir R, Michaelis M, Devor M (1999) Membrane potential oscillations in dorsal root ganglion neurons: role in normal electrogenesis and neuropathic pain. J Neurosci 19:8589-8596. Medline

Amir R, Kocsis JD, Devor M (2005) Multiple interacting sites of ectopic spike electrogenesis in primary sensory neurons. J Neurosci 25:25762585. CrossRef Medline

Ariav G, Polsky A, Schiller J (2003) Submillisecond precision of the inputoutput transformation function mediated by fast sodium dendritic spikes in basal dendrites of CA1 pyramidal neurons. J Neurosci 23:7750-7758. Medline

Bean BP (2007) The action potential in mammalian central neurons. Nat Rev Neurosci 8:451-465. CrossRef Medline

Benedetti BL, Glazewski S, Barth AL (2009) Reliable and precise neuronal firing during sensory plasticity in superficial layers of primary somatosensory cortex. J Neurosci 29:11817-11827. CrossRef Medline

Biella G, Salvadori G, Sotgiu ML (1999) Multifractal analysis of wide dynamic range neuron discharge profiles in normal rats and in rats with sciatic nerve constriction. Somatosens Mot Res 16:89-102. CrossRef Medline

Cao XY, Xu H, Wu LJ, Li XY, Chen T, Zhuo M (2009) Characterization of intrinsic properties of cingulate pyramidal neurons in adult mice after nerve injury. Mol Pain 5:73. CrossRef Medline

Cardoso-Cruz H, Lima D, Galhardo V (2013a) Impaired spatial memory performance in a rat model of neuropathic pain is associated with reduced hippocampus-prefrontal cortex connectivity. J Neurosci 33:2465-2480. CrossRef Medline

Cardoso-Cruz H, Sousa M, Vieira JB, Lima D, Galhardo V (2013b) Prefrontal cortex and mediodorsal thalamus reduced connectivity is associated with spatial working memory impairment in rats with inflammatory pain. Pain 154:2397-2406. CrossRef Medline

Cathala L, Brickley S, Cull-Candy S, Farrant M (2003) Maturation of EPSCs and intrinsic membrane properties enhances precision at a cerebellar synapse. J Neurosci 23:6074-6085. Medline

Colgin LL, Denninger T, Fyhn M, Hafting T, Bonnevie T, Jensen O, Moser MB, Moser EI (2009) Frequency of gamma oscillations routes flow of information in the hippocampus. Nature 462:353-357. CrossRef Medline

Cudmore RH, Fronzaroli-Molinieres L, Giraud P, Debanne D (2010) Spiketime precision and network synchrony are controlled by the homeostatic regulation of the D-type potassium current. J Neurosci 30:12885-12895. CrossRef Medline

Descalzi G, Li XY, Chen T, Mercaldo V, Koga K, Zhuo M (2012) Rapid synaptic potentiation within the anterior cingulate cortex mediates trace fear learning. Mol Brain 5:6. CrossRef Medline

Devor M (1991) Neuropathic pain and injured nerve: peripheral mechanisms. Br Med Bull 47:619-630. Medline

Devor M (2006) Sodium channels and mechanisms of neuropathic pain. J Pain 7:S3-S12. CrossRef Medline

Devor M (2009) Ectopic discharge in Abeta afferents as a source of neuropathic pain. Exp Brain Res 196:115-128. CrossRef Medline

Epsztein J, Sola E, Represa A, Ben-Ari Y, Crépel V (2010) A selective interplay between aberrant EPSPKA and INaP reduces spike timing precision in dentate granule cells of epileptic rats. Cereb Cortex 20:898-911. CrossRef Medline

Ermentrout GB, Galán RF, Urban NN (2008) Reliability, synchrony and noise. Trends Neurosci 31:428-434. CrossRef Medline

Faisal AA, Selen LP, Wolpert DM (2008) Noise in the nervous system. Nat Rev Neurosci 9:292-303. CrossRef Medline

Fetz EE (1997) Temporal coding in neural populations? Science 278:19011902. CrossRef Medline

Frankland PW, Bontempi B (2005) The organization of recent and remote memories. Nat Rev Neurosci 6:119-130. CrossRef Medline

Fricker D, Miles R (2000) EPSP amplification and the precision of spike timing in hippocampal neurons. Neuron 28:559-569. CrossRef Medline

Gao J, Wu X, Owyang C, Li Y (2006) Enhanced responses of the anterior cingulate cortex neurones to colonic distension in viscerally hypersensitive rats. J Physiol 570:169-183. CrossRef Medline

Han HC, Lee DH, Chung JM (2000) Characteristics of ectopic discharges in a rat neuropathic pain model. Pain 84:253-261. CrossRef Medline

Harris KD, Csicsvari J, Hirase H, Dragoi G, Buzsáki G (2003) Organization of cell assemblies in the hippocampus. Nature 424:552-556. CrossRef Medline

Harsch A, Robinson HP (2000) Postsynaptic variability of firing in rat cortical neurons: the roles of input synchronization and synaptic NMDA receptor conductance. J Neurosci 20:6181-6192. Medline

Harvey PJ, Li X, Li Y, Bennett DJ (2006) 5-HT2 receptor activation facilitates a persistent sodium current and repetitive firing in spinal motoneurons of rats with and without chronic spinal cord injury. J Neurophysiol 96:1158-1170. CrossRef Medline

Kovalsky Y, Amir R, Devor M (2009) Simulation in sensory neurons reveals a key role for delayed $\mathrm{Na}+$ current in subthreshold oscillations and ectopic discharge: implications for neuropathic pain. J Neurophysiol 102: 1430-1442. CrossRef Medline

Lenz FA, Tasker RR, Dostrovsky JO, Kwan HC, Gorecki J, Hirayama T, Murphy JT (1987) Abnormal single-unit activity recorded in the somatosensory thalamus of a quadriplegic patient with central pain. Pain 31:225-236. CrossRef Medline

Lenz FA, Garonzik IM, Zirh TA, Dougherty PM (1998) Neuronal activity in the region of the thalamic principal sensory nucleus (ventralis caudalis) in patients with pain following amputations. Neuroscience 86:1065-1081. CrossRef Medline

Li XY, Ko HG, Chen T, Descalzi G, Koga K, Wang H, Kim SS, Shang Y, Kwak C, Park SW, Shim J, Lee K, Collingridge GL, Kaang BK, Zhuo M (2010) Alleviating neuropathic pain hypersensitivity by inhibiting PKMzeta in the anterior cingulate cortex. Science 330:1400-1404. CrossRef Medline

Li XY, Chen T, Descalzi G, Koga K, Qiu S, Zhuo M (2012) Characterization of neuronal intrinsic properties and synaptic transmission in layer I of anterior cingulate cortex from adult mice. Mol Pain 8:53. CrossRef Medline

Mainen ZF, Sejnowski TJ (1995) Reliability of spike timing in neocortical neurons. Science 268:1503-1506. CrossRef Medline

Múnera A, Cuestas DM, Troncoso J (2012) Peripheral facial nerve lesions induce changes in the firing properties of primary motor cortex layer 5 pyramidal cells. Neuroscience 223:140-151. CrossRef Medline

Mutso AA, Radzicki D, Baliki MN, Huang L, Banisadr G, Centeno MV, Radulovic J, Martina M, Miller RJ, Apkarian AV (2012) Abnormalities in hippocampal functioning with persistent pain. J Neurosci 32:5747-5756. CrossRef Medline

Parnaudeau S, O’Neill PK, Bolkan SS, Ward RD, Abbas AI, Roth BL, Balsam PD, Gordon JA, Kellendonk C (2013) Inhibition of mediodorsal thalamus disrupts thalamofrontal connectivity and cognition. Neuron 77 : 1151-1162. CrossRef Medline

Paxinos G, Watson D (1998) The rat brain in stereotaxic coordinates. New York: Academic.

Rodriguez-Molina VM, Aertsen A, Heck DH (2007) Spike timing and reliability in cortical pyramidal neurons: effects of EPSC kinetics, input synchronization and background noise on spike timing. PLoS One 2:e319. CrossRef Medline

Rutishauser U, Ross IB, Mamelak AN, Schuman EM (2010) Human memory strength is predicted by theta-frequency phase-locking of single neurons. Nature 464:903-907. CrossRef Medline

Steenland HW, Li XY, Zhuo M (2012) Predicting aversive events and terminating fear in the mouse anterior cingulate cortex during trace fear conditioning. J Neurosci 32:1082-1095. CrossRef Medline

Stuart GJ, Häusser M (2001) Dendritic coincidence detection of EPSPs and action potentials. Nat Neurosci 4:63-71. CrossRef Medline

Szatmáry B, Izhikevich EM (2010) Spike-timing theory of working memory. PLoS Comput Biol 6:e1000879. CrossRef Medline

Tiesinga P, Fellous JM, Sejnowski TJ (2008) Regulation of spike timing in visual cortical circuits. Nat Rev Neurosci 9:97-107. CrossRef Medline

Vadakkan KI, Jia YH, Zhuo M (2005) A behavioral model of neuropathic pain induced by ligation of the common peroneal nerve in mice. J Pain 6:747756. CrossRef Medline

Vervaeke K, Hu H, Graham LJ, Storm JF (2006) Contrasting effects of the persistent $\mathrm{Na}+$ current on neuronal excitability and spike timing. Neuron 49:257-270. CrossRef Medline

Wang H, Xu H, Wu LJ, Kim SS, Chen T, Koga K, Descalzi G, Gong B, Vadak- 
kan KI, Zhang X, Kaang BK, Zhuo M (2011) Identification of an adenylyl cyclase inhibitor for treating neuropathic and inflammatory pain. Sci Transl Med 3:65ra3. CrossRef Medline

Wei F, Qiu CS, Kim SJ, Muglia L, Maas JW, Pineda VV, Xu HM, Chen ZF, Storm DR, Muglia LJ, Zhuo M (2002) Genetic elimination of behavioral sensitization in mice lacking calmodulin-stimulated adenylyl cyclases. Neuron 36:713-726. CrossRef Medline

Wu LJ, Toyoda H, Zhao MG, Lee YS, Tang J, Ko SW, Jia YH, Shum FW, Zerbinatti CV, Bu G, Wei F, Xu TL, Muglia LJ, Chen ZF, Auberson YP, Kaang BK, Zhuo M (2005) Upregulation of forebrain NMDA NR2B receptors contributes to behavioral sensitization after inflammation. J Neurosci 25:11107-11116. Medline

Xu H, Wu LJ, Wang H, Zhang X, Vadakkan KI, Kim SS, Steenland HW, Zhuo M (2008) Presynaptic and postsynaptic amplifications of neuropathic pain in the anterior cingulate cortex. J Neurosci 28:74457453. CrossRef Medline

Yu J, Qian H, Chen N, Wang JH (2011) Quantal glutamate release is essential for reliable neuronal encodings in cerebral networks. PLoS One 6:e25219. CrossRef Medline
Zhang Y, Wang N, Wang JY, Chang JY, Woodward DJ, Luo F (2011) Ensemble encoding of nociceptive stimulus intensity in the rat medial and lateral pain systems. Mol Pain 7:64. CrossRef Medline

Zhao MG, Toyoda H, Lee YS, Wu LJ, Ko SW, Zhang XH, Jia Y, Shum F, Xu H, Li BM, Kaang BK, Zhuo M (2005) Roles of NMDA NR2B subtype receptor in prefrontal long-term potentiation and contextual fear memory. Neuron 47:859-872. CrossRef Medline

Zhao MG, Ko SW, Wu LJ, Toyoda H, Xu H, Quan J, Li J, Jia Y, Ren M, Xu ZC, Zhuo M (2006) Enhanced presynaptic neurotransmitter release in the anterior cingulate cortex of mice with chronic pain. J Neurosci 26:89238930. CrossRef Medline

Zhuo M (2008) Cortical excitation and chronic pain. Trends Neurosci 31: 199-207. CrossRef Medline

Zhuo M (2013) Long-term potentiation in the anterior cingulate cortex and chronic pain. Philos Trans R Soc Lond B Biol Sci 369:20130146. CrossRef Medline

Zsiros V, Hestrin S (2005) Background synaptic conductance and precision of EPSP-spike coupling at pyramidal cells. J Neurophysiol 93:3248-3256. CrossRef Medline 